\title{
Characterization and function of medium and large extracellular vesicles from plasma and urine by surface antigens and Annexin V
}

\author{
Ko Igami ${ }^{1,2,3}$, Takeshi Uchiumi ${ }^{\text {Corresp., 1,4 }}{ }^{\text {, Saori Ueda }}{ }^{1}$, Kazuyuki Kamioka ${ }^{2,5}$, Daiki Setoyama ${ }^{1}$, Kazuhito Gotoh ${ }^{1}$, \\ Masaru Akimoto ${ }^{1}$, Shinya Matsumoto ${ }^{1}$, Dongchon Kang ${ }^{1}$ \\ ${ }^{1}$ Department of Clinical Chemistry and Laboratory Medicine, Kyushu University Graduate School of Medical Sciences, Kyushu University, Fukuoka, Japan \\ 2 Kyushu Pro Search Limited Liability Partnership, Fukuoka, Japan \\ 3 Business Management Division, Clinical Laboratory Business Segment, LSI Medience Corporation, Tokyo, Japan \\ ${ }^{4}$ Clinical Chemistry, Division of Biochemical Science and Technology, Department of Health Sciences, Faculty of Medical Sciences,, Kyushu University, \\ Fukuoka, Japan \\ 5 Department of Medical Solutions, LSI Medience Corporation, Tokyo, Japan \\ Corresponding Author: Takeshi Uchiumi \\ Email address: uchiumi@cclm.med.kyushu-u.ac.jp
}

Background. Extracellular vesicles (EVs) are released by most cell types and are involved in multiple basic biological processes. Medium/large EVs (m/lEVs), which is different size from exosome, plays an important role in the coagulation in blood, and is secreted from cancer cells, etc., suggesting functions related to malignant transformation. The $\mathrm{m} / \mathrm{IEVs}$ levels in blood or urine may help unravel pathophysiological findings in many diseases. However, it remains unclear how many naturally-occurring m/IEV subtypes exist as well as how their characteristics and functions differ from one another. Methods. We used the blood and urinal sample from each 10 healthy donors for analysis. Using a flow cytometer, we focus on characterization of EVs with large sizes (>200nm) that are different from exosomes. We also searched for a membrane protein for characterization with a flow cytometer using shotgun proteomics. Then we identified $\mathrm{m} / \mathrm{IEVs}$ pelleted from plasma and urine samples by differential centrifugation and characterized by flow cytometry. Results. Using proteomic profiling, we identified several proteins involved in $\mathrm{m} / \mathrm{IEV}$ biogenesis including adhesion molecules, peptidases and exocytosis regulatory proteins. In healthy human plasma, we could distinguish $\mathrm{m} / \mathrm{IEVs}$ derived from platelets, erythrocytes, monocytes/macrophages, T and B cells, and vascular endothelial cells with more than two positive surface antigens. The ratio of phosphatidylserine appearing on the membrane surface differed depending on the cell-derived $\mathrm{m} / \mathrm{IEVs}$. In urine, $50 \%$ of $\mathrm{m} / \mathrm{IEVs}$ were Annexin $V$ negative but contained various membrane peptidases derived from renal tubular villi. Urinary $\mathrm{m} / \mathrm{IEV}$, but not plasma $\mathrm{m} / \mathrm{IEVs}$, showed peptidase activity. The knowledge of the new characteristics is considered to be useful as a diagnostic material 
and the newly developed method suggests the possibility of clinical application. 
1 Characterization and function of medium and large extracellular vesicles from plasma and urine

2 by surface antigens and Annexin $\mathrm{V}$

3

4 Ko Igami $^{1,2,3}$, Takeshi Uchiumi ${ }^{1,4 *}$, Saori Ueda ${ }^{1}$, Kazuyuki Kamioka ${ }^{2,5}$, Daiki Setoyama ${ }^{1}$,

5 Kazuhito Gotoh ${ }^{1}$, Masaru Akimoto ${ }^{1}$, Shinya Matsumoto ${ }^{1}$ and Dongchon Kang ${ }^{1}$

$7{ }^{1}$ Department of Clinical Chemistry and Laboratory Medicine, Kyushu University Graduate

8 School of Medical Sciences, 3-1-1, Maidashi, Higashi-ku, Fukuoka 812-8582, Japan.

$9{ }^{2}$ Kyushu Pro Search Limited Liability Partnership, 4-1, Kyudaishimmachi, Nishi-ku, Fukuoka, 10 819-0388, Japan.

$11{ }^{3}$ Business Management Division, Clinical Laboratory Business Segment, LSI Medience

12 Corporation, 13-4, Uchikanda 1-chome, Chiyoda-ku, Tokyo, 101-8517, Japan.

$13{ }^{4}$ Clinical Chemistry, Division of Biochemical Science and Technology, Department of Health

14 Sciences, Faculty of Medical Sciences, Kyushu University, Fukuoka, Japan

$15{ }^{5}$ Department of Medical Solutions, LSI Medience Corporation, 3-30-1, Shimura, Itabashi-ku, 16 Tokyo, 174-8555, Japan.

*Correspondence Author:

19 Takeshi Uchiumi, Department of Clinical Chemistry and Laboratory Medicine, Kyushu 8582, Japan. 


\section{Abstract}

Background. Extracellular vesicles (EVs) are released by most cell types and are involved in multiple basic biological processes. Medium/large EVs (m/lEVs), which is different size from exosome, plays an important role in the coagulation in blood, and is secreted from cancer cells, etc., suggesting functions related to malignant transformation. The $\mathrm{m} / \mathrm{lEVs}$ levels in blood or urine may help unravel pathophysiological findings in many diseases. However, it remains unclear how many naturally-occurring m/lEV subtypes exist as well as how their characteristics and functions differ from one another.

Methods. We used the blood and urinal sample from each 10 healthy donors for analysis. Using a flow cytometer, we focus on characterization of EVs with large sizes $(>200 \mathrm{~nm})$ that are different from exosomes. We also searched for a membrane protein for characterization with a flow cytometer using shotgun proteomics. Then we identified $\mathrm{m} / \mathrm{lEVs}$ pelleted from plasma and urine samples by differential centrifugation and characterized by flow cytometry.

Results. Using proteomic profiling, we identified several proteins involved in $\mathrm{m} / \mathrm{lEV}$ biogenesis including adhesion molecules, peptidases and exocytosis regulatory proteins. In healthy human plasma, we could distinguish $\mathrm{m} / \mathrm{lEVs}$ derived from platelets, erythrocytes, monocytes/macrophages, T and B cells, and vascular endothelial cells with more than two positive surface antigens. The ratio of phosphatidylserine appearing on the membrane surface differed depending on the cell-derived $\mathrm{m} / \mathrm{lEVs}$. In urine, $50 \%$ of $\mathrm{m} / \mathrm{lEVs}$ were Annexin $\mathrm{V}$ negative but contained various membrane peptidases derived from renal tubular villi. Urinary $\mathrm{m} / \mathrm{lEVs}$, but not plasma $\mathrm{m} / \mathrm{lEVs}$, showed peptidase activity. The knowledge of the new characteristics is considered to be useful as a diagnostic material and the newly developed method suggests the possibility of clinical application. 


\section{Introduction}

Extracellular vesicles (EVs) play essential roles in cell-cell communication and are diagnostically significant molecules. EVs are secreted from most cell types under normal and pathophysiological conditions (Iraci et al. 2016; Ohno et al. 2013). These membrane vesicles can be detected in many human body fluids and are thought to have signaling functions in interactions between cells. Analysis of EVs may have applications in therapy, prognosis, and biomarker development in various fields. The hope is that using EV analysis, clinicians will be able to detect the presence of disease as well as to classify its progression using noninvasive methods such as liquid biopsy (Boukouris \& Mathivanan 2015; Piccin 2014; Piccin et al. 2015a; Piccin et al. 2017a; Piccin et al. 2017b; Piccin et al. 2015b).

Medium/large extracellular vesicles (m/lEVs) can be classified based on their cellular origins, biological functions and biogenesis (El Andaloussi et al. 2013). In a broad sense, they can be classified into $\mathrm{m} / \mathrm{lEVs}$ with diameters of 100-1000 nm diameter (membrane blebs) and smaller EVs (e.g. exosomes) with diameters of 30-150 nm (Raposo \& Stoorvogel 2013; Robbins \& Morelli 2014). The $\mathrm{m} / \mathrm{lEVs}$ are generated by direct outward budding from the plasma membrane (D'Souza-Schorey \& Clancy 2012), while smaller EVs (e.g. exosomes) are produced via the endosomal pathway with formation of intraluminal vesicles by inward budding of multivesicular bodies (MVBs) (Raposo \& Stoorvogel 2013). In this study, we analyzed the physical characteristics of EVs from $200 \mathrm{~nm}$ to $800 \mathrm{~nm}$ in diameter which we refer to as $\mathrm{m} / \mathrm{lEVs}$ as per the MISEV2018 guidelines (Thery et al. 2018).

Recently, the clinical relevance of EVs has attracted significant attention. In particular, $\mathrm{m} / \mathrm{lEVs}$ play an important role in tumor invasion (Clancy et al. 2015). $\mathrm{m} / \mathrm{lEVs}$ in blood act as a coagulant factor and have been associated with sickle cell disease, sepsis, thrombotic thrombocytopenic purpura, and other diseases (Piccin et al. 2007; Piccin et al. 2017a; Piccin et al. 2017b). A possible role for urinary $\mathrm{m} / \mathrm{lEVs}$ in diabetic nephropathy was also reported (Sun et al. 2012). In recent years, the clinical applications of exosomes have been developed (Yoshioka et al. 2014). However, because characterization of exosomes is analytically challenging, determining the cells and tissues from which exosomes are derived can be difficult. $\mathrm{m} / \mathrm{lEVs}$ are 
76 generated differently from exosomes (Mathivanan et al. 2010) but are similar in size and contain

77 many of the same surface antigens. It is widely hypothesized that complete separation of

78 exosomes and $\mathrm{m} / \mathrm{lEVs}$ is likely to be a major challenge, and more effective techniques to purify

79 and characterize $\mathrm{m} / \mathrm{lEV}$ s would be extremely valuable.

80 In this study, we focused on $\mathrm{m} / \mathrm{lEVs}$ in plasma and urine, which are representative body fluids in

81 clinical laboratories. We purified for $\mathrm{m} / \mathrm{lEVs}$ based on differential centrifugation and

82 characterized $\mathrm{m} / \mathrm{lEVs}$ by flow cytometry and mass spectrometry analysis and described the basic

83 properties (characterizing surface antigen and orientation of phosphatidylserine and activity of

84 the enzymes) of $\mathrm{m} / \mathrm{lEV}$ subpopulations in blood and urine.

85

86 
87

88

\section{Materials and Methods}

\section{Antibodies and other reagents}

The following monoclonal antibodies against human surface antigens were used in this study: anti-CD5(clone: L17F12), anti-CD15 (clone: W6D3), anti-CD41(clone: HIP8), anti-CD45(clone: HI30), anti-CD59 (clone: p282), anti-CD61 (clone: VI-PL2), anti-CD105 (clone: 43A3), antiCD146(clone: P1H12), anti-CD235a (clone: HI264), anti-CD10 (clone: HI10a), anti-CD13 (clone: WM15), anti-CD26 (clone: BA5b), anti-CD227 (MUC1) (clone: 16A). All antibodies were purchased from BioLegend® (San Diego, CA). FITC-conjugated Annexin V was purchased from BD Biosciences (New Jersey, USA). We used the SPHERO ${ }^{\mathrm{TM}}$ Nano Fluorescent Particle Size Standard Kit, Yellow (diameters 0.22, 0.45, 0.88 and $1.35 \mu \mathrm{m}$ ) from Spherotech Inc. for size validation. Normal mouse IgG was purchased from Wako Chemicals (Tokyo, Japan). APC-conjugated normal mouse IgG was produced using the Mix-n-Stain ${ }^{\text {TM APC }}$ Antibody Labeling kit from Biotium Inc. Dithiothreitol (DTT) was purchased from Wako Chemicals (Tokyo, Japan). We conducted phase transfer surfactant experiments using "MPEX PTS Reagents for MS” purchased from GL Sciences Inc. and "Trypsin, TPCK Treated" purchased from Thermo Fisher Scientific ${ }^{\mathrm{TM}}$. Iodoacetamide was purchased from Wako Chemicals (Tokyo, Japan).

\section{Samples}

All studies were approved by the Institutional Review Board of the Kyushu University Hospital, Kyushu University (29-340). Blood samples were collected from 20 male and female participants (23-48 years of age) who were apparently healthy. We received the informed consent from all participants of this study. Samples were collected using a 22-gauge butterfly needle and a slow-fill syringe. After discarding the initial 2-3 $\mathrm{mL}$, blood was dispensed into collection tubes containing ethylenediamine tetra acetic acid (EDTA) (1.6 mg/mL blood). Urine was collected from 20 male healthy subjects (23-46 years of age). The first morning void urine was used for the experiments. The urine samples were collected in a sterile container. In particular, we confirmed that sample used for analysis by flow cytometer were derived from 
114 healthy donors by measuring blood count and creatinine in blood and total urine protein

115 (Supplementary Table.S1).

116 Isolation of plasma m/lEVs

117 Essentially platelet-free plasma (PFP) was prepared from EDTA-treated blood by double 118 centrifugation at $2,330 \times g$ for $10 \mathrm{~min}$. To assess residual platelets remaining in this sample, we 119 measured platelet number using the ADVIA ${ }^{2}$ 2120i Hematology System (SIEMENS

120 Healthineers, Erlangen Germany). The number of platelets in this sample was below the limit of 121 detection $\left(1 \times 10^{3}\right.$ cells $\left./ \mu \mathrm{L}\right)$. We used a centrifugation method to obtain $\mathrm{m} / \mathrm{lEVs}$. In an effort to 122 ensure our approach could be applied to clinical testing, we chose a simple and easy method for 123 pretreatment. In an ISEV position paper (Mateescu et al. 2017), Thery's group referred to 124 vesicles sedimenting at $100,000 \times g$ as "small EVs" rather than exosomes, those pelleting at 125 intermediate speed (lower than 20,000 $\times g$ ) as "medium EVs" (including microvesicles and 126 ectosomes) and those pelleting at low speed (e.g., $2000 \times g$ ) as "large EVs". Because these 127 definitions are less biologically meaningful but more experimentally tractable than previously128 applied exosome/microvesicle definitions, we attempted biological characterization through 129 subsequent shotgun and flow cytometry analysis.

130 In flow cytometric analysis, the volume of PFP used in each assay was $0.6 \mathrm{~mL}$ from each 131 donor. In electron microscopy, the volume of PFP used was $3 \mathrm{~mL}$. Samples were independent 132 and were treated individually prior to each measurement. PFP was centrifuged at $18,900 \times g$ for $13330 \mathrm{~min}$ in a fixed-angle rotor. The $\mathrm{m} / \mathrm{lEV}$ pellet obtained after centrifugation was reconstituted 134 by vortex mixing (1-2 min) with an equivalent volume of Dulbecco's phosphate-buffered saline 135 (DPBS), $\mathrm{pH}$ 7.4. The solution was centrifuged at $18,900 \times \mathrm{g}$ for $30 \mathrm{~min}$ again and the supernatant 136 was discarded.

137 Isolation of urinary $\mathrm{m} / \mathrm{lEVs}$

138 For isolation of urinary $\mathrm{m} / \mathrm{lEVs}$, we modified a urinary exosome extraction protocol (Fernandez139 Llama et al. 2010). The centrifugation conditions were identical for plasma and urine so that the 140 size and the density of $\mathrm{m} / \mathrm{lEVs}$ were similar, enabling comparison of plasma and urinary $\mathrm{m} / \mathrm{lEVs}$. 
In flow cytometric analysis, the volume of urine used for each assay was $1.2 \mathrm{~mL}$ from

142 each donor. In electron microscopy, the volume of urine used was $15 \mathrm{~mL}$. Samples were

143 independent and were treated individually prior to each measurement. Collected urine was

144 centrifuged at $2,330 \times g$ for 10 min twice. The supernatant was centrifuged at $18,900 \times g$ for 30

$145 \mathrm{~min}$ in a fixed-angle rotor. The $\mathrm{m} / \mathrm{lEV}$ pellet obtained from centrifugation was reconstituted by

146 vortex mixing (1-2 min) with $0.2 \mathrm{~mL}$ of DPBS followed by incubation with DTT (final

147 concentration $10 \mathrm{mg} / \mathrm{mL}$ ) at $37^{\circ} \mathrm{C}$ for $10-15 \mathrm{~min}$. The samples were centrifuged again at 18,900

$148 \times g$ for $30 \mathrm{~min}$ and the supernatant was discarded. Addition of DTT, a reducing agent, reduced

149 the formation of Tamm-Horsfall protein (THP) polymers. THP monomers were removed from

$150 \mathrm{~m} / \mathrm{lEVs}$ after centrifugation. DTT-containing DPBS solutions were filtered through $0.1-\mu \mathrm{m}$

151 filters (Millipore).

\section{Flow cytometric analysis of $\mathrm{m} / \mathrm{lEVs}$}

153 After resuspending $\mathrm{m} / \mathrm{lEV}$ pellets in $60 \mu \mathrm{L}$ of DPBS, we added saturating concentrations of 154 several labelled antibodies, Annexin V and normal mouse IgG and incubated the tubes in the 155 dark, without stirring, for 15-30 min at room temperature. In one case, we added labelled 156 antibodies directly to $60 \mu \mathrm{L}$ of PFP for staining. We resuspended stained fractions in Annexin V 157 binding buffer (BD Biosciences: $10 \mathrm{mM}$ HEPES, $0.14 \mathrm{mM} \mathrm{NaCl}, 2.5 \mathrm{mM} \mathrm{CaCl}_{2}, \mathrm{pH} 7.4$ ) for

158 analysis by flow cytometry. DPBS and Annexin V binding buffer were filtered through $0.1-\mu \mathrm{m}$ 159 filters (Millipore). Flow cytometry was performed using a FACSVerse ${ }^{\text {TM }}$ flow cytometer (BD 160 Biosciences). The flow cytometer was equipped with $405 \mathrm{~nm}, 488 \mathrm{~nm}$ and $638 \mathrm{~nm}$ lasers to 161 detect up to 13 fluorescent parameters. The flow rate was $12 \mu \mathrm{L} / \mathrm{min}$. Forward scatter voltage 162 was set to 381 , side scatter voltage was set to 340 , and each threshold was set to 200. Details of 163 excitation (Ex.) and emission (Em.) wavelengths as well as voltages described in supplements 164 Fig. Flow cytometry was performed using FACSuite ${ }^{\mathrm{TM}}$ software (BD Biosciences) and data were 165 analyzed using FlowJo software. The authors have applied for the following patents for the 166 characterization method of $\mathrm{m} / \mathrm{lEVs}$ isolated from plasma and urine with a flow cytometer: 167 JP2018-109402(plasma) and JP2018-109403(urine).

\section{Nanoparticle tracking analysis (NTA)}


169 NTA measurements were performed using a NanoSight LM10 (NanoSight, Amesbury, United

170 Kingdom). After resuspending mEV pellets in $50 \mu \mathrm{L}$ of DPBS, samples were diluted eight-fold

171 (plasma) and 100-fold (urinary) with PBS prior to measurement. Particles in the laser beam

172 undergo Brownian motion and videos of these particle movements are recorded. NTA 2.3

173 software then analyses the video and determines the particle concentration and the size

174 distribution of the particles. Twenty-five frames per second were recorded for each sample at

175 appropriate dilutions with a "frames processed" setting of 1500 . The detection threshold was set

176 at "7 Multi" and at least 1,000 tracks were analyzed for each video.

\section{Electron microscopy}

178 For immobilization, we added $100 \mu \mathrm{L}$ of PBS and another $100 \mu \mathrm{L}$ of immobilization solution 179 (4\% paraformaldehyde, 4\% glutaraldehyde, $0.1 \mathrm{M}$ phosphate buffer, $\mathrm{pH} 7.4$ ) to $\mathrm{m} / \mathrm{EV}$ pellets. 180 After stirring, we incubated at $4^{\circ} \mathrm{C}$ for $1 \mathrm{~h}$. For negative staining, the samples were adsorbed to

181 formvar film-coated copper grids (400 mesh) and stained with $2 \%$ phosphotungstic acid, pH 7.0, 182 for $30 \mathrm{~s}$. For observation and imaging, the grids were observed using a transmission electron 183 microscope (JEM-1400Plus; JEOL Ltd., Tokyo, Japan) at an acceleration voltage of $100 \mathrm{kV}$. 184 Digital images $(3296 \times 2472$ pixels $)$ were taken with a CCD camera (EM-14830RUBY2; JEOL 185 Ltd., Tokyo, Japan).

\section{Protein digestion}

We used approximately $50 \mathrm{~mL}$ of pooled healthy plasma and $100 \mathrm{~mL}$ of pooled healthy male urine from five healthy subjects for digestion of $\mathrm{m} / \mathrm{lEV}$.

In plasma the following process is the same as "Isolation of plasma $\mathrm{m} / \mathrm{lEVs}$ " section. We repeated $18,900 \times \mathrm{g}$ centrifugation washing steps three times to reduce levels of contaminating free plasma proteins and small EVs for shotgun analysis. After the last centrifugation, we removed supernatants and froze the samples.

193 In urine the following process is the same as "Isolation of urinary $\mathrm{m} / \mathrm{lEVs}$ " section. We repeated washing steps twice (after DTT treatment) to reduce levels of contaminating free urinary proteins and small EVs for shotgun analysis. We removed supernatants and froze the 196 samples. 
To discover characterizing surface antigen by flowcytometry, the sample was digested using a phase transfer surfactant-aided procedure so that many hydrophobic membrane proteins could be detected (Chen et al. 2017). The precipitated frozen fractions of plasma and urine were thawed at $37^{\circ} \mathrm{C}$, and then $\mathrm{m} / \mathrm{lEVs}$ were solubilized in $250 \mu \mathrm{L}$ of lysis buffer containing $12 \mathrm{mM}$ sodium deoxycholate and $12 \mathrm{mM}$ sodium lauroyl sarcosinate in $100 \mathrm{mM}$ Tris $\cdot \mathrm{HCl}, \mathrm{pH} 8.5$. After incubating for $5 \mathrm{~min}$ at $95^{\circ} \mathrm{C}$, the solution was sonicated using an ultrasonic homogenizer. Protein concentrations of the solutions were measured using a bicinchoninic acid assay (Pierce ${ }^{\mathrm{TM}}$ BCA Protein Assay Kit; Thermo Fisher Scientific).

Twenty microliters of the dissolved pellet (30 $\mu \mathrm{g}$ protein) were used for protein digestion.

Proteins were reduced and alkylated with $1 \mathrm{mM}$ DTT and $5.5 \mathrm{mM}$ iodoacetamide at $25^{\circ} \mathrm{C}$ for 60 min. Trypsin was added to a final enzyme:protein ratio of 1:100 (wt/wt) for overnight digestion. Digested peptides were acidified with $0.5 \%$ trifluoroacetic acid (final concentration) and $100 \mu \mathrm{L}$ of ethyl acetate was added for each $100 \mu \mathrm{L}$ of digested m/lEVs. The mixture was shaken for 2 $\min$ and then centrifuged at $15,600 \times g$ for 2 min to obtain aqueous and organic phases. The aqueous phase was collected and desalted using a GL-Tip SDB column (GL Sciences Inc).

\section{LC-MS/MS analysis}

213 Digested peptides were dissolved in $40 \mu \mathrm{L}$ of $0.1 \%$ formic acid containing $2 \%(\mathrm{v} / \mathrm{v})$ acetonitrile

214 and $2 \mu \mathrm{L}$ were injected into an Easy-nLC 1000 system (Thermo Fisher Scientific). Peptides were separated on an Acclaim PepMap ${ }^{\mathrm{TM}}$ RSLC column $(15 \mathrm{~cm} \times 50 \mu \mathrm{m}$ inner diameter $)$ containing C18 resin $\left(2 \mu \mathrm{m}, 100 \AA\right.$; Thermo Fisher Scientific $\left.{ }^{\mathrm{TM}}\right)$, and an Acclaim PepMap ${ }^{\mathrm{TM}} 100$ trap column ( $2 \mathrm{~cm} \times 75 \mu \mathrm{m}$ inner diameter) containing C18 resin $(3 \mu \mathrm{m}, 100 \AA$; Thermo Fisher Scientific ${ }^{\mathrm{TM}}$ ). The mobile phase consisted of $0.1 \%$ formic acid in ultrapure water (buffer A). The elution buffer was $0.1 \%$ formic acid in acetonitrile (buffer B); a linear 200 min gradient from $0 \%-40 \%$ buffer B was used at a flow rate of $200 \mathrm{~nL} / \mathrm{min}$. The Easy-nLC 1000 was coupled via a nanospray Flex ion source (Thermo Fisher Scientific ${ }^{\mathrm{TM}}$ ) to a Q Exactive ${ }^{\mathrm{TM}}$ Orbitrap (Thermo Fisher Scientific $\left.{ }^{\mathrm{TM}}\right)$. The mass spectrometer was operated in data-dependent mode, in which a full-scan MS (from 350 to 1,400 m/z with a resolution of 70,000, automatic gain control (AGC) $3 \mathrm{E}+06$, maximum injection time $50 \mathrm{~ms}$ ) was followed by MS/MS on the 20 most intense ions 
225 (AGC 1E+05, maximum injection time $100 \mathrm{~ms}, 4.0 \mathrm{~m} / \mathrm{z}$ isolation window, fixed first mass 100 $226 \mathrm{~m} / \mathrm{z}$, normalized collision energy $32 \mathrm{eV}$ ).

\section{Proteome Data Analysis}

228 Raw MS files were analyzed using Proteome Discoverer software version 1.4 (Thermo Fisher

229 Scientific ${ }^{\mathrm{TM}}$ ) and peptide lists were searched against the Uniprot Proteomes-Homo sapiens

230 FASTA (Last modified November 17, 2018) using the Sequest HT algorithm. Initial precursor

231 mass tolerance was set at $10 \mathrm{ppm}$ and fragment mass tolerance was set at 0.6 Da. Search criteria

232 included static carbamidomethylation of cysteine (+57.0214 Da), dynamic oxidation of

233 methionine (+15.995 Da) and dynamic acetylation (+43.006 Da) of lysine and arginine residues.

234 Gene ontology analysis and gene enrichment analysis

235 We conducted GO analysis using DAVID (https://david.ncifcrf.gov) to categorize the

236 proteins identified by shotgun analysis and used Metascape

237 (http://metascape.org/gp/index.html\#/main/step1) for gene enrichment analysis. We uploaded the 238 UNIPROT_ACCESSION No. for each protein.

\section{Extracellular vesicle preparation from isolated erythrocytes}

Whole blood was collected by the same method as above and centrifuged at 2,330 $\times g$

for $10 \mathrm{~min}$. After removal of the buffy coat and supernatant plasma, the remaining erythrocytes were washed three times by centrifugation at $2,330 \times g$ for $10 \mathrm{~min}$ and the erythrocyte pellet was resuspended in DPBS. EVs were generated from the washed erythrocytes by stimulation in the presence of $2.5 \mathrm{mM} \mathrm{CaCl}_{2}\left(10 \mathrm{mM}\right.$ HEPES, $\left.0.14 \mathrm{mM} \mathrm{NaCl}, 2.5 \mathrm{mM} \mathrm{CaCl}_{2}, \mathrm{pH} 7.4\right)$ for $1 \mathrm{~h}$ at room temperature under rotating conditions. Erythrocytes were removed by centrifugation at $2,330 \times g$ for 10 min and the EV rich supernatant was subsequently centrifuged $(18,900 \times g$ for 30 min) to pellet the EVs. EVs were resuspended in DPBS.

DPP4 activity was measured in the plasma and urine of six individuals (different from plasma donors). The method was previously published in part (Kawaguchi et al. 2010). DPP4 activity was measured via the fluorescence intensity of 7-amino-4-methylcoumarin (AMC) after

252 its dissociation from the synthetic substrate (Gly-Pro-AMC $\bullet \mathrm{HBr}$ ) catalyzed by DPP4. 
253 Experiments were performed in 96-well black plates. Titrated AMC was added to each well to 254 prepare a standard curve. Fluorescence intensity was measured after incubating substrate with 255 urine samples for $10 \mathrm{~min}$. The enzyme reaction was terminated by addition of acetic acid. The 256 fluorescence intensity (Ex. $=380 \mathrm{~nm}$ and Em. $=460 \mathrm{~nm}$ ) was measured using Varioskan Flash 257 (Thermo Fisher Scientific ${ }^{\mathrm{TM}}$ ). DPP4 activity assays were performed by Kyushu Pro Search LLP 258 (Fukuoka, Japan). 


\section{Results}

260

261

262

263

264

265

266

267

268

269

270

271

272

273

274

275

276

277

278

279

280

281

282

283

284

285

286

\section{Isolation and characterization of $\mathrm{m} / \mathrm{IEVs}$ from plasma and urine.}

The workflow for the isolation and enrichment of $\mathrm{m} / \mathrm{lEVs}$ for flow cytometric analyses is illustrated in Fig.1A and 1B. m/lEVs from human plasma samples were isolated by high-speed centrifugation, an approach used in previous studies (Jayachandran et al. 2012). For isolation of $\mathrm{m} / \mathrm{lEVs}$ from urine, DTT, a reducing agent, was used to remove THP polymers because these non-specifically interact with IgGs.

Transmission electron microscopy revealed that almost all $\mathrm{m} / \mathrm{lEVs}$ were small, closed vesicles with a size of approximately $200 \mathrm{~nm}$ that were surrounded by lipid bilayer (Fig. 1C-H). In plasma, we observed EVs whose membranes were not stained either inside or on the surface (Fig. 1C, 1D); we also observed EVs whose forms were slightly distorted (Fig. 1E). In urine, a group of EVs with uneven morphology and EVs with interior structures were observed (Fig. 1F1H). Apoptotic bodies, cellular debris, and protein aggregates were not detected.

No EVs with diameters greater than $800 \mathrm{~nm}$ were observed by NTA (Supplementary Fig.S1) and flow cytometry can detect only EVs with diameters larger than $200 \mathrm{~nm}$. Together, these data suggested that we characterized m/lEVs between $200 \mathrm{~nm}$ and $800 \mathrm{~nm}$ in diameter from plasma and urine by flow cytometry analysis. We observed the m/lEVs less than $100 \mathrm{~nm}$ by NTA because of some contamination or degradation after purification (Supplementary Fig.S1).” Side-scatter events from size calibration beads of (diameters: $0.22,0.45,0.88$ and 1.35 $\mu \mathrm{m}$ ) were resolved from instrument noise using a FACS Verse flow cytometer (Supplementary Fig.S2A). Inspection of the side-scatter plot indicated that $0.22 \mu \mathrm{m}$ was the lower limit for bead detection. More than $90 \%$ of $\mathrm{m} / \mathrm{lEVs}$ isolated from plasma and urine showed side-scatter intensities lower than those of 0.88 - $\mu \mathrm{m}$ calibration beads (Fig. 2A-D). m/1EVs were heterogeneous in size, with diameters ranging from $200-800 \mathrm{~nm}$ in plasma and urine (Fig. 2AD). Fluorescently-labeled mouse IgG was used to exclude nonspecific IgG-binding fractions (Supplementary Fig.S2 B and C). In this experiment, we characterized m/lEVs with diameters ranging from 200-800 $\mathrm{nm}$. NTA analysis shows less than 100nm size particles in the plasma fraction extracted by centrifugation, but we focused on particles over 200nm using a flow 
287 cytometer. Using these methods, we observed an average of $8 \times 10^{5}$ and $1 \times 10^{5} \mathrm{~m} / 1 \mathrm{EVs}$ in each $\mathrm{mL}$ 288 of plasma and urine by flow cytometry observation.

289 Shotgun proteomic analysis of plasma and urine EVs.

290 To analyze the protein components and discover characterizing surface antigen of $\mathrm{m} / \mathrm{lEVs}$

291 present in plasma and urine of five healthy individuals, we performed LC-MS/MS proteomic 292 analysis. In this analysis, in order to prevent small EVs contamination, the washing process by 293 centrifugation was increased compared to other analyses (Materials and Methods). A total of 593 294 and 1,793 proteins were identified in m/lEVs from plasma and urine, respectively (Fig. 3A and 295 Supplementary Table S2 and Table S3). Scoring counts using the SequestHT algorithm for the 296 top 20 most abundant proteins are shown in Table 1 and 2. We detected cytoskeleton-related 297 protein such as actin, ficolin-3 and filamin and cell-surface antigen such as CD5, band3 and 298 CD41 in plasma. We also identified actin filament-related proteins such as ezrin, radixin, ankylin and moesin which play key roles in cell surface adhesion, migration and organization in both plasma and urine. In urine, several types of peptidases (membrane alanine aminopeptidase or CD13; neprilysin or CD10; DPP4 or CD26) and MUC1 (mucin 1 or CD227) were detected in high abundance, and these proteins were used to characterize $\mathrm{m} / \mathrm{lEVs}$ by flow cytometric analysis (Table 2 and Supplementary Table S3). We demonstrated that the isolated $\mathrm{m} / \mathrm{lEVs}$ showed high expression of tubulin and actinin, while the tetraspanins CD9 and CD81 that are often used as exosome markers were only weakly identified. Especially in plasma, small EV (exosome) markers TSG101, VPS4 and Alix were not observed in this m/lEVs fraction (Supplementary Table S4). These data suggest that $\mathrm{m} / \mathrm{lEVs}$ differ from small EVs including exosomes.

As shown in Fig. 3A and Supplementary Fig S3, about 10\% of urinary EVs proteins were also identified in plasma EVs. Urinary EVs in the presence of blood contaminants were also

311 observed in previous studies (Smalley et al. 2008). These result suggest that $\mathrm{m} / \mathrm{lEVs}$ in plasma

312 were excreted in the urine via renal filtration and not reabsorbed. Gene ontology analysis of the 313 identified proteins indicated overall similar cellular components in plasma and urine $\mathrm{m} / \mathrm{lEVs}$

314 (Fig. 3B). The results of gene set enrichment analysis by metascape are shown for plasma and 
315 urine m/lEVs (Fig. 3C, D and Supplementary Table S5 and Table S6). The most commonly-

316 observed functions in both plasma and urine were "regulated exocytosis", "hemostasis" and

317 "vesicle-mediated transport". In plasma, several functions of blood cells were observed,

318 including "complement and coagulation cascades" and "immune response". Moreover, analysis

319 of urinary EVs showed several characteristic functions including "transport of small molecules",

320 "metabolic process" and "cell projection assembly". This may reflect the nature of the kidney,

321 the urinary system and tubular villi. These data demonstrate the power of data-driven biological

322 analyses.

323 Characterization of plasma EVs by flow cytometry.

324 Next, we characterized $\mathrm{m} / \mathrm{lEVs}$ in plasma by flow cytometry using antibodies against

325 several surface antigens and Annexin V. To eliminate nonspecific adsorption, we excluded the

326 mouse IgG-positive fraction. (Supplementary Fig.S2B) Eliminating non-specific reactions to

327 antibodies is important in using human body fluids as diagnostic materials for immunological

328 measurements. By adding mouse IgG-APC to the system, we observed accurate flow cytometry

329 image in which specific surface antigens were recognized by following two points: 1) blocking

330 of non-specific reaction sites, 2) gate-out of positive non-specific reaction. We characterized

331 positive $\mathrm{m} / \mathrm{lEV}$ s using surface antigens detected by shotgun proteomic analysis and Annexin $\mathrm{V}$

332 (Fig. 4A-L).

333 To characterize $\mathrm{m} / \mathrm{lEVs}$ derived from erythrocytes, $\mathrm{T}$ and $\mathrm{B}$ cells,

334 macrophages/monocytes, granulocytes, platelets and endothelial cells, we selected nine antigens

335 described in Fig. 4A. Two or more antigens were used for characterization of m/lEVs: for

336 example, CD59 and CD235a double-positive and CD45-negative m/lEVs were classified as

337 erythrocyte-derived m/lEVs (Supplementary Fig. S4B). We confirmed that m/lEVs isolated

338 from erythrocytes in vitro and erythrocytes derived $\mathrm{m} / \mathrm{lEVs}$ from plasma are characterized by

339 CD59 and CD235a double-positive and CD45-negative (Supplementary Fig. S5). Determined

340 positive area by addition of EDTA (Supplementary Fig. S2D), we also show Annexin V staining

341 for the $\mathrm{m} / \mathrm{lEVs}$ corresponding to these five classifications (Fig. 4B-L). We integrated these

342 characterizations and assessed the distribution of EV classifications among ten healthy subjects 
343 (Fig. 4M). The results suggested that no major differences in the ratios of fractions in these ten

344 subjects and thus these definitions may be used for pathological analysis.

345 We found that $10 \%$ and $35 \%$ of $\mathrm{m} / \mathrm{lEVs}$ were derived from erythrocytes and platelets, 346 respectively. However, only $0.5 \%, 0.6 \%$ and $0.1 \%$ of $\mathrm{m} / \mathrm{lEVs}$ were derived from macrophages,

347 leukocytes and endothelial cells, respectively suggesting that the ratio of $\mathrm{m} / \mathrm{lEVs}$ of different

348 cellular origins is dependent on the number of cells present in plasma (Fig. 4M). We also

349 observed that most $\mathrm{m} / \mathrm{lEV}$ s derived from erythrocytes and macrophages were Annexin $\mathrm{V}$ positive

350 (Fig. $4 \mathrm{~N}$ and O). By contrast, many Annexin V negative m/lEVs were identified among platelet-

351 and $\mathrm{T}$ and $\mathrm{B}$ cell-derived $\mathrm{m} / \mathrm{lEVs}$ (Fig. $4 \mathrm{P}$ and Q). Especially about erythrocyte-derived m/lEVs

352 other studies have shown high percentages of phosphatidylserine-positive(:Annexin V positive)

$353 \mathrm{~m} / \mathrm{lEVs}$ after red blood cell storage under blood bank conditions that these results are consistent

354 (Gao et al. 2013)(Xiong et al. 2011).

In general, it is known that microparicle in blood are known to be exposed to PS on the

356

357

358

359

360

361

362

363

364

365

366

367

368

369

370

surface, which is verified by being positive by Annexin5 staining. We found that the degree of exposure of phosphatidylserine to the membrane surface was vary depending on the cell derived from annexin $\mathrm{V}$ staining. Thus, the characteristics of $\mathrm{m} / \mathrm{lEVs}$ can be determined in detail by using AnnexinV and antigenicity. These results suggested that the degree of exposing PS are cell-type specific and that release mechanisms may differ among cell types.

\section{Characterization of urinary EVs by flow cytometry and enzyme activity assay.}

In urine, we first removed aggregated $\mathrm{m} / \mathrm{lEVs}$ and residual THP polymers using labelled normal mouse IgG (Supplementary Fig.S2C). By removing the THP polymer by DTT treatment, many immunological non-specific reactions in flow cytometry observation were eliminated, and the remaining non-specific reactions were completely excluded from the observed image by mouse IgG-positive gating-out (Supplementary Fig.S2F). To characterize urinary m/lEVs, we used surface antigens detected by shotgun proteomic analysis including CD10 (neprilysin), CD13 (alanine aminopeptidase), CD26 (DPP4) and CD227 (MUC1) (Fig. 5A-F). Many m/lEVs in the observation area were triple-positive for CD10, CD13 and CD26, but negative for Annexin V (Fig. 5B-D, Supplementary Fig. S6). Furthermore, MUC1-positive EVs were both Annexin V 
371 positive and negative in roughly equivalent frequencies (Fig. 5B, E and F). These results

372 suggested that $\mathrm{m} / \mathrm{lEV}$ s containing peptidases were released by outward budding directly from the

373 cilial membrane of renal proximal tubule epithelial cells. The results of integrating these

374 characterizations and the distribution of EV classifications among ten healthy subjects are shown

375 (Fig. 5G-I). These data indicated no major differences in the ratio among these populations,

376 suggesting that our methodology was reliable for $\mathrm{m} / \mathrm{lEV}$ analysis.

377 We next verified the CD26 peptidase enzyme activities of $\mathrm{m} / \mathrm{lEVs}$ in plasma and urine

378 from six individuals. We prepared three fractions: (i) "whole," in which debris were removed

379 after low speed centrifugation, (ii) "m/lEVs" and (iii) "free (supernatant)" both of which were

380 obtained via high speed centrifugation $(18,900 \times g$ for $30 \mathrm{~min})($ Fig. $5 \mathrm{~J})$. We found that more than

$38120 \%$ of DPP4 activity in whole urine was contributed by the EV fraction (Fig. $5 \mathrm{~K}$ and

382 Supplementary Fig. S7). By contrast, there was no peptidase activity associated with plasma

$383 \mathrm{~m} / \mathrm{lEVs}$ (Fig. 5L). These results suggested that functional CD26 peptidase activity is present in

$384 \mathrm{~m} / \mathrm{lEVs}$ in urine, which may be useful for pathological analysis. 
386

387

388

389

390

391

392

393

394

395

396

397

398

399

400

401

402

403

404

405

406

407

408

409

410

411

412

413

\section{Discussion}

In this study, we analyzed $\mathrm{m} / \mathrm{lEVs}$ using various analytic techniques and found the following four major results. First, it was possible to characterize m/lEVs using multiple surface markers. Second, $\mathrm{m} / \mathrm{lEVs}$ bear functional enzymes with demonstrable enzyme activity on the vesicle surface. Trird, there are probability of differences in asymmetry of membrane lipids by derived cells. Finally, there was little variation $\mathrm{m} / \mathrm{lEVs}$ in the plasma and urine of healthy individuals, indicating that our method is useful for identifying cell-derived $\mathrm{m} / \mathrm{lEVs}$ in these body fluids.

We isolated $\mathrm{m} / \mathrm{lEVs}$ from plasma and urine that were primarily $200-800 \mathrm{~nm}$ in diameter as shown by transmission electron microscopy. A large proportion of proteins detected in $\mathrm{m} / \mathrm{lEVs}$ using shotgun proteomic analysis were categorized as plasma membrane proteins. Isolation of $\mathrm{m} / \mathrm{lEVs}$ by centrifugation is a classical technique, but in the present study we further separated and classified the $\mathrm{m} / \mathrm{lEV}$ s according to their cell types of origin by flow cytometry. The results indicated the validity of the differential centrifugation method (Biro et al. 2003; Piccin et al. 2015a).

Pang et al. (Pang et al. 2018) reported that integrin outside-in signaling is an important mechanism for microvesicle formation, in which the procoagulant phospholipid phosphatidylserine (PS) is efficiently externalized to release PS-exposed microvesicles (MVs). These platelet-derived Annexin V positive MVs were induced by application of a pulling force via an integrin ligand such as shear stress. This exposure of PS allows binding of important coagulation factors, enhancing the catalytic efficiencies of coagulation enzymes. We observed that $50 \%$ of $\mathrm{m} / \mathrm{lEV}$ s derived from leukocytes and platelets were Annexin V positive, suggesting that release PS-positive $\mathrm{m} / \mathrm{lEV}$ s during activation, inflammation, and injury. It would be interesting to further investigate whether the ratio of Annexin $\mathrm{V}$ positive $\mathrm{m} / \mathrm{lEV}$ s from platelets or leukocytes was an important diagnostic factor for inflammatory disease or tissue injury. In urinary $\mathrm{m} / \mathrm{lEVs}$, we identified aminopeptidases such as CD10, CD13 and CD26 which are localized in proximal renal tubular epithelial cells. The functions of these proteins relating to exocytosis were categorized by gene enrichment analysis. The cilium in the kidney is 
414 the site at which a variety of membrane receptors, enzymes and signal transduction molecules

415 critical to many cellular processes function. In recent years, ciliary ectosomes - bioactive

416 vesicles released from the surface of the cilium - have attracted attention (Nager et al. 2017;

417 Phua et al. 2017; Wood \& Rosenbaum 2015). We also identified ciliary ectosome formation

418 ESCRT complexes proteins (CHAMP; Supplementary Table S3 and 4) in proteomic analyses,

419 suggesting that the possibility that these proteins were biomarkers of kidney disease. Because

420 triple peptidase positive $\mathrm{m} / \mathrm{lEVs}$ were negative for Annexin $\mathrm{V}$, the mechanism of budding from

421 cells may not be dependent on scramblase. (Wood \& Rosenbaum 2015)

422 Platelet-derived $\mathrm{m} / \mathrm{lEVs}$ are the most abundant population of extracellular vesicles in

423 blood, and their presence (Piccin et al. 2007) and connection with tumor formation were reported

424 in a recent study (Zmigrodzka et al. 2016). In our study, platelet-derived EVs were observed in

425 healthy subjects and had the highest abundance of Annexin V-positive EVs. In plasma,

426 leukocyte-derived EVs were defined as CD11b/CD66b- or CD15-positive (Sarlon-Bartoli et al.

427 2013). We characterized macrophage/monocyte/granulocyte- and T/B cell-derived EVs based on

428 two specific CD antigens, and we confirmed that EVs derived from these cells were very rare.

429 Importantly, there was little variation in the cellular origins of $\mathrm{m} / \mathrm{lEVs}$ in samples from ten

430 healthy individuals, indicating that this method was useful for identifying cell-derived m/lEVs.

431 We plan to examine $\mathrm{m} / \mathrm{lEVs}$ differences in patients with these diseases in the near future.

432 Erythrocyte-derived EVs were also characterized by their expression of CD235a and glycophorin

433 A by flow cytometry (Ferru et al. 2014; Zecher et al. 2014).

434 We also characterized $\mathrm{m} / \mathrm{lEVs}$ in urine. In kidneys and particularly in the renal tubule,

435 CD10, CD13, CD26 can be detected in high abundance by immunohistochemical staining

436 (website: The Human Protein Atlas). CD10/CD13-double positive labeling can be used for

437 isolation and characterization of primary proximal tubular epithelial cells from human kidney

438 (Van der Hauwaert et al. 2013). DPP4 (CD26) is a potential biomarker in urine for diabetic

439 kidney disease and the presence of urinary m/1EV-bound DPP4 has been demonstrated (Sun et

440 al. 2012). The presence of peptidases on the $\mathrm{m} / \mathrm{lEV}$ surface, and their major contribution to

441 peptidase activity in whole urine (Sun et al. 2012), may suggest a functional contribution to 
442 reabsorption in the proximal tubules. These observations suggested that the ratio of DPP activity

443 between $\mathrm{m} / \mathrm{lEVs}$ and total urine can be an important factor in the diagnosis of kidney disease.

$444 \quad$ MUC1 can also be detected in kidney and urinary bladder by immunohistochemical

445 staining (website: The Human Protein Atlas). Significant increases of MUC1 expression in

446 cancerous tissue and in the intermediate zone compared with normal renal tissue distant from the

447 tumor was observed (Borzym-Kluczyk et al. 2015). In any case, MUC1-positive EVs are thought

448 to be more likely to be derived from the tubular epithelium or the urothelium.

Conclusions

451

Use of EVs as diagnostic reagents with superior disease and organ specificity for liquid biopsy samples is a possibility. This protocol will allow further study and in depth characterization of EV profiles in large patient groups for clinical applications. We are going to attempt to identify novel biomarkers by comparing healthy subjects and patients with various diseases.

\section{ACKNOWLEDGEMENTS}

458

459

460

461

462

463

464

465

466

467

We thank lab members for reagents, discussions, and critical reading of the manuscript. We are grateful to LSI Medience Corporation for generous support during this study. This work was supported by a Grant-in-Aid for Scientific Research from the Japan Society for the Promotion of Science (JSPS; grant numbers \#25253041, \#17H01550 and 15H04764) and research funding from LSI Medience Corporation. We thank Edanz Group (www.edanzediting.com/ac) for editing a draft of this manuscript.

\section{Author Contributions}

K.I. and T.U. designed the research and wrote the manuscript. S.U., K.G., S.M. and M.A carried out the experiments, obtained reagents and materials, and conducted data analysis. D.S. and N.A. 
468 contributed to network analysis. D.K, K.K. and T.U. contributed to flavonoid identification. All

469 authors read and approved the final manuscript.

470

471 Competing Interests

472 The authors have read the journal's policy and would like to declare the following competing 473 interests: K.I. is a full-time employee of LSI Medience Corporation. K.K. is a full-time employee 474 of LSI Medience Corporation. K.I. is also seconded to Kyushu Pro Search Limited Liability 475 Partnership from LSI Medience Corporation. K.K. also serves as Kyushu Pro Search Limited 476 Liability Partnership and LSI Medience Corporation and is the representative officer of Kyushu 477 Pro Search Limited Liability Partnership.

478

479

480 
481

482

483

484

485

486

487

488

489

490

491

492

493

494

495

496

497

498

499

500

501

502

503

504

505

506

507

508

509

510

511

512

513

\section{Reference}

Biro E, Sturk-Maquelin KN, Vogel GM, Meuleman DG, Smit MJ, Hack CE, Sturk A, and Nieuwland R. 2003. Human cell-derived microparticles promote thrombus formation in vivo in a tissue factordependent manner. $J$ Thromb Haemost 1:2561-2568.

Borzym-Kluczyk M, Radziejewska I, and Cechowska-Pasko M. 2015. Increased expression of MUC1 and sialyl Lewis antigens in different areas of clear renal cell carcinoma. Clin Exp Nephrol 19:732-737. 10.1007/s10157-014-1013-y

Boukouris S, and Mathivanan S. 2015. Exosomes in bodily fluids are a highly stable resource of disease biomarkers. Proteomics Clin Appl 9:358-367. 10.1002/prca.201400114

Chen IH, Xue L, Hsu CC, Paez JS, Pan L, Andaluz H, Wendt MK, Iliuk AB, Zhu JK, and Tao WA. 2017. Phosphoproteins in extracellular vesicles as candidate markers for breast cancer. Proc Natl Acad Sci U S A 114:3175-3180. 10.1073/pnas.1618088114

Clancy JW, Sedgwick A, Rosse C, Muralidharan-Chari V, Raposo G, Method M, Chavrier P, and D'SouzaSchorey C. 2015. Regulated delivery of molecular cargo to invasive tumour-derived microvesicles. Nat Commun 6:6919. 10.1038/ncomms7919

D'Souza-Schorey C, and Clancy JW. 2012. Tumor-derived microvesicles: shedding light on novel microenvironment modulators and prospective cancer biomarkers. Genes Dev 26:1287-1299. $10.1101 / \mathrm{gad} .192351 .112$

El Andaloussi S, Lakhal S, Mager I, and Wood MJ. 2013. Exosomes for targeted siRNA delivery across biological barriers. Adv Drug Deliv Rev 65:391-397. 10.1016/j.addr.2012.08.008

Fernandez-Llama P, Khositseth S, Gonzales PA, Star RA, Pisitkun T, and Knepper MA. 2010. TammHorsfall protein and urinary exosome isolation. Kidney Int 77:736-742. 10.1038/ki.2009.550

Ferru E, Pantaleo A, Carta F, Mannu F, Khadjavi A, Gallo V, Ronzoni L, Graziadei G, Cappellini MD, and Turrini F. 2014. Thalassemic erythrocytes release microparticles loaded with hemichromes by redox activation of p72Syk kinase. Haematologica 99:570-578. 10.3324/haematol.2013.084533

Gao Y, Lv L, Liu S, Ma G, and Su Y. 2013. Elevated levels of thrombin - generating microparticles in stored red blood cells. Vox sanguinis 105:11-17.

Iraci N, Leonardi T, Gessler F, Vega B, and Pluchino S. 2016. Focus on Extracellular Vesicles: Physiological Role and Signalling Properties of Extracellular Membrane Vesicles. Int J Mol Sci 17:171. 10.3390/ijms17020171

Jayachandran M, Miller VM, Heit JA, and Owen WG. 2012. Methodology for isolation, identification and characterization of microvesicles in peripheral blood. J Immunol Methods 375:207-214. 10.1016/j.jim.2011.10.012 
514 Kawaguchi M, Okabe T, Terai T, Hanaoka K, Kojima H, Minegishi I, and Nagano T. 2010. A time-resolved

515

516

517

518

519

520

521

522

523

524

525

526

527

528

529

530

531

532

533

534

535

536

537

538

539

540

541

542

543

544

545

546

547

fluorescence probe for dipeptidyl peptidase 4 and its application in inhibitor screening. Chemistry 16:13479-13486. 10.1002/chem.201001077

Mateescu B, Kowal EJ, van Balkom BW, Bartel S, Bhattacharyya SN, Buzas EI, Buck AH, de Candia P, Chow FW, Das S, Driedonks TA, Fernandez-Messina L, Haderk F, Hill AF, Jones JC, Van KeurenJensen KR, Lai CP, Lasser C, Liegro ID, Lunavat TR, Lorenowicz MJ, Maas SL, Mager I, Mittelbrunn M, Momma S, Mukherjee K, Nawaz M, Pegtel DM, Pfaffl MW, Schiffelers RM, Tahara H, Thery C, Tosar JP, Wauben MH, Witwer KW, and Nolte-'t Hoen EN. 2017. Obstacles and opportunities in the functional analysis of extracellular vesicle RNA - an ISEV position paper. J Extracell Vesicles 6:1286095. 10.1080/20013078.2017.1286095

Mathivanan S, Ji H, and Simpson RJ. 2010. Exosomes: extracellular organelles important in intercellular communication. J Proteomics 73:1907-1920. 10.1016/j.jprot.2010.06.006

Nager AR, Goldstein JS, Herranz-Perez V, Portran D, Ye F, Garcia-Verdugo JM, and Nachury MV. 2017. An Actin Network Dispatches Ciliary GPCRs into Extracellular Vesicles to Modulate Signaling. Cell 168:252-263 e214. 10.1016/j.cell.2016.11.036

Ohno S, Ishikawa A, and Kuroda M. 2013. Roles of exosomes and microvesicles in disease pathogenesis. Adv Drug Deliv Rev 65:398-401. 10.1016/j.addr.2012.07.019

Pang A, Cui Y, Chen Y, Cheng N, Delaney MK, Gu M, Stojanovic-Terpo A, Zhu C, and Du X. 2018. Shear-induced integrin signaling in platelet phosphatidylserine exposure, microvesicle release, and coagulation. Blood 132:533-543. 10.1182/blood-2017-05-785253

Phua SC, Chiba S, Suzuki M, Su E, Roberson EC, Pusapati GV, Setou M, Rohatgi R, Reiter JF, Ikegami K, and Inoue T. 2017. Dynamic Remodeling of Membrane Composition Drives Cell Cycle through Primary Cilia Excision. Cell 168:264-279 e215. 10.1016/j.cell.2016.12.032

Piccin A. 2014. Endothelial Microparticles and Endothelial Damage:'The Tip and the Iceberg'. Acta haematologica 132:199-199.

Piccin A, Murphy C, Eakins E, Kunde J, Corvetta D, Di Pierro A, Negri G, Guido M, Sainati L, Mc Mahon C, Smith OP, and Murphy W. 2015a. Circulating microparticles, protein C, free protein S and endothelial vascular markers in children with sickle cell anaemia. J Extracell Vesicles 4:28414. 10.3402/jev.v4.28414

Piccin A, Murphy WG, and Smith OP. 2007. Circulating microparticles: pathophysiology and clinical implications. Blood Rev 21:157-171. 10.1016/j.blre.2006.09.001

Piccin A, Sartori MT, Bisogno G, Van Schilfgaarde M, Saggiorato G, Pierro AM, Corvetta D, Marcheselli L, Andrea M, and Gastl G. 2017a. New insights into sinusoidal obstruction syndrome. Internal medicine journal 47:1173-1183.

Peer] An. Chem. reviewing PDF | (ACHEM-2019:09:41205:2:0:NEW 20 Dec 2019) 
548

549

550

551

552

553

554

555

556

557

558

559

560

561

562

563

564

565

566

567

568

569

570

571

572

573

574

575

576

577

578

579

580

581

582

583

Piccin A, Steurer M, Feistritzer C, Murphy C, Eakins E, Van Schilfgaarde M, Corvetta D, Di Pierro AM, Pusceddu I, and Marcheselli L. 2017b. Observational retrospective study of vascular modulator changes during treatment in essential thrombocythemia. Translational Research 184:21-34.

Piccin A, Van Schilfgaarde M, and Smith O. 2015b. The importance of studying red blood cells microparticles. Blood Transfusion 13:172.

Raposo G, and Stoorvogel W. 2013. Extracellular vesicles: exosomes, microvesicles, and friends. $J$ Cell Biol 200:373-383. 10.1083/jcb.201211138

Robbins PD, and Morelli AE. 2014. Regulation of immune responses by extracellular vesicles. Nat Rev Immunol 14:195-208. 10.1038/nri3622

Sarlon-Bartoli G, Bennis Y, Lacroix R, Piercecchi-Marti MD, Bartoli MA, Arnaud L, Mancini J, Boudes A, Sarlon E, Thevenin B, Leroyer AS, Squarcioni C, Magnan PE, Dignat-George F, and Sabatier F. 2013. Plasmatic level of leukocyte-derived microparticles is associated with unstable plaque in asymptomatic patients with high-grade carotid stenosis. J Am Coll Cardiol 62:1436-1441. 10.1016/j.jacc.2013.03.078

Smalley DM, Sheman NE, Nelson K, and Theodorescu D. 2008. Isolation and identification of potential urinary microparticle biomarkers of bladder cancer. $J$ Proteome Res 7:2088-2096. 10.1021/pr700775x

Sun AL, Deng JT, Guan GJ, Chen SH, Liu YT, Cheng J, Li ZW, Zhuang XH, Sun FD, and Deng HP. 2012. Dipeptidyl peptidase-IV is a potential molecular biomarker in diabetic kidney disease. Diab Vasc Dis Res 9:301-308. 10.1177/1479164111434318

Thery C, Witwer KW, Aikawa E, Alcaraz MJ, Anderson JD, Andriantsitohaina R, Antoniou A, Arab T, Archer F, Atkin-Smith GK, Ayre DC, Bach JM, Bachurski D, Baharvand H, Balaj L, Baldacchino S, Bauer NN, Baxter AA, Bebawy M, Beckham C, Bedina Zavec A, Benmoussa A, Berardi AC, Bergese P, Bielska E, Blenkiron C, Bobis-Wozowicz S, Boilard E, Boireau W, Bongiovanni A, Borras FE, Bosch S, Boulanger CM, Breakefield X, Breglio AM, Brennan MA, Brigstock DR, Brisson A, Broekman ML, Bromberg JF, Bryl-Gorecka P, Buch S, Buck AH, Burger D, Busatto S, Buschmann D, Bussolati B, Buzas EI, Byrd JB, Camussi G, Carter DR, Caruso S, Chamley LW, Chang YT, Chen C, Chen S, Cheng L, Chin AR, Clayton A, Clerici SP, Cocks A, Cocucci E, Coffey RJ, Cordeiro-da-Silva A, Couch Y, Coumans FA, Coyle B, Crescitelli R, Criado MF, D'SouzaSchorey C, Das S, Datta Chaudhuri A, de Candia P, De Santana EF, De Wever O, Del Portillo HA, Demaret T, Deville S, Devitt A, Dhondt B, Di Vizio D, Dieterich LC, Dolo V, Dominguez Rubio AP, Dominici M, Dourado MR, Driedonks TA, Duarte FV, Duncan HM, Eichenberger RM, Ekstrom K, El Andaloussi S, Elie-Caille C, Erdbrugger U, Falcon-Perez JM, Fatima F, Fish JE, Flores-Bellver M, Forsonits A, Frelet-Barrand A, Fricke F, Fuhrmann G, Gabrielsson S, GamezValero A, Gardiner C, Gartner K, Gaudin R, Gho YS, Giebel B, Gilbert C, Gimona M, Giusti I, Goberdhan DC, Gorgens A, Gorski SM, Greening DW, Gross JC, Gualerzi A, Gupta GN, 
584

585

586

587

588

589

590

591

592

593

594

595

596

597

598

599

600

601

602

603

604

605

606

607

608

609

610

611

612

613

614

615

616

617

618

Gustafson D, Handberg A, Haraszti RA, Harrison P, Hegyesi H, Hendrix A, Hill AF, Hochberg FH, Hoffmann KF, Holder B, Holthofer H, Hosseinkhani B, Hu G, Huang Y, Huber V, Hunt S, Ibrahim AG, Ikezu T, Inal JM, Isin M, Ivanova A, Jackson HK, Jacobsen S, Jay SM, Jayachandran M, Jenster G, Jiang L, Johnson SM, Jones JC, Jong A, Jovanovic-Talisman T, Jung S, Kalluri R, Kano SI, Kaur S, Kawamura Y, Keller ET, Khamari D, Khomyakova E, Khvorova A, Kierulf P, Kim KP, Kislinger T, Klingeborn M, Klinke DJ, 2nd, Kornek M, Kosanovic MM, Kovacs AF, Kramer-Albers EM, Krasemann S, Krause M, Kurochkin IV, Kusuma GD, Kuypers S, Laitinen S, Langevin SM, Languino LR, Lannigan J, Lasser C, Laurent LC, Lavieu G, Lazaro-Ibanez E, Le Lay S, Lee MS, Lee YXF, Lemos DS, Lenassi M, Leszczynska A, Li IT, Liao K, Libregts SF, Ligeti E, Lim R, Lim SK, Line A, Linnemannstons K, Llorente A, Lombard CA, Lorenowicz MJ, Lorincz AM, Lotvall J, Lovett J, Lowry MC, Loyer X, Lu Q, Lukomska B, Lunavat TR, Maas SL, Malhi H, Marcilla A, Mariani J, Mariscal J, Martens-Uzunova ES, Martin-Jaular L, Martinez MC, Martins VR, Mathieu M, Mathivanan S, Maugeri M, McGinnis LK, McVey MJ, Meckes DG, Jr., Meehan KL, Mertens I, Minciacchi VR, Moller A, Moller Jorgensen M, Morales-Kastresana A, Morhayim J, Mullier F, Muraca M, Musante L, Mussack V, Muth DC, Myburgh KH, Najrana T, Nawaz M, Nazarenko I, Nejsum P, Neri C, Neri T, Nieuwland R, Nimrichter L, Nolan JP, Nolte-'t Hoen EN, Noren Hooten N, O'Driscoll L, O'Grady T, O'Loghlen A, Ochiya T, Olivier M, Ortiz A, Ortiz LA, Osteikoetxea X, Ostergaard O, Ostrowski M, Park J, Pegtel DM, Peinado H, Perut F, Pfaffl MW, Phinney DG, Pieters BC, Pink RC, Pisetsky DS, Pogge von Strandmann E, Polakovicova I, Poon IK, Powell BH, Prada I, Pulliam L, Quesenberry P, Radeghieri A, Raffai RL, Raimondo S, Rak J, Ramirez MI, Raposo G, Rayyan MS, Regev-Rudzki N, Ricklefs FL, Robbins PD, Roberts DD, Rodrigues SC, Rohde E, Rome S, Rouschop KM, Rughetti A, Russell AE, Saa P, Sahoo S, Salas-Huenuleo E, Sanchez C, Saugstad JA, Saul MJ, Schiffelers RM, Schneider R, Schoyen TH, Scott A, Shahaj E, Sharma S, Shatnyeva O, Shekari F, Shelke GV, Shetty AK, Shiba K, Siljander PR, Silva AM, Skowronek A, Snyder OL, 2nd, Soares RP, Sodar BW, Soekmadji C, Sotillo J, Stahl PD, Stoorvogel W, Stott SL, Strasser EF, Swift S, Tahara H, Tewari M, Timms K, Tiwari S, Tixeira R, Tkach M, Toh WS, Tomasini R, Torrecilhas AC, Tosar JP, Toxavidis V, Urbanelli L, Vader P, van Balkom BW, van der Grein SG, Van Deun J, van Herwijnen MJ, Van Keuren-Jensen K, van Niel G, van Royen ME, van Wijnen AJ, Vasconcelos MH, Vechetti IJ, Jr., Veit TD, Vella LJ, Velot E, Verweij FJ, Vestad B, Vinas JL, Visnovitz T, Vukman KV, Wahlgren J, Watson DC, Wauben MH, Weaver A, Webber JP, Weber V, Wehman AM, Weiss DJ, Welsh JA, Wendt S, Wheelock AM, Wiener Z, Witte L, Wolfram J, Xagorari A, Xander P, Xu J, Yan X, Yanez-Mo M, Yin H, Yuana Y, Zappulli V, Zarubova J, Zekas V, Zhang JY, Zhao Z, Zheng L, Zheutlin AR, Zickler AM, Zimmermann P, Zivkovic AM, Zocco D, and Zuba-Surma EK. 2018. Minimal information for studies of extracellular vesicles 2018 (MISEV2018): a position statement

Peer] An. Chem. reviewing PDF | (ACHEM-2019:09:41205:2:0:NEW 20 Dec 2019) 
619

620

621

622

623

624

625

626

627

628

629

630

631

632

633

634

635

636

637

638

639

640

641 of the International Society for Extracellular Vesicles and update of the MISEV2014 guidelines. $J$ Extracell Vesicles 7:1535750. 10.1080/20013078.2018.1535750

Van der Hauwaert C, Savary G, Gnemmi V, Glowacki F, Pottier N, Bouillez A, Maboudou P, Zini L, Leroy $\mathrm{X}$, Cauffiez C, Perrais M, and Aubert S. 2013. Isolation and characterization of a primary proximal tubular epithelial cell model from human kidney by CD10/CD13 double labeling. PLoS One 8:e66750. 10.1371/journal.pone.0066750

Wood CR, and Rosenbaum JL. 2015. Ciliary ectosomes: transmissions from the cell's antenna. Trends Cell Biol 25:276-285. 10.1016/j.tcb.2014.12.008

Xiong Z, Cavaretta J, Qu L, Stolz DB, Triulzi D, and Lee JS. 2011. Red blood cell microparticles show altered inflammatory chemokine binding and release ligand upon interaction with platelets. Transfusion 51:610-621.

Yoshioka Y, Kosaka N, Konishi Y, Ohta H, Okamoto H, Sonoda H, Nonaka R, Yamamoto H, Ishii H, Mori M, Furuta K, Nakajima T, Hayashi H, Sugisaki H, Higashimoto H, Kato T, Takeshita F, and Ochiya T. 2014. Ultra-sensitive liquid biopsy of circulating extracellular vesicles using ExoScreen. Nat Commun 5:3591. 10.1038/ncomms4591

Zecher D, Cumpelik A, and Schifferli JA. 2014. Erythrocyte-derived microvesicles amplify systemic inflammation by thrombin-dependent activation of complement. Arterioscler Thromb Vasc Biol 34:313-320. 10.1161/ATVBAHA.113.302378

Zmigrodzka M, Guzera M, Miskiewicz A, Jagielski D, and Winnicka A. 2016. The biology of extracellular vesicles with focus on platelet microparticles and their role in cancer development and progression. Tumour Biol 37:14391-14401. 10.1007/s13277-016-5358-6 


\section{Table 1 (on next page)}

Twenty most abundant proteins identified in plasma m/lEVs 
1 Table 1. Twenty most abundant proteins identified in plasma $\mathbf{m} / \mathrm{lEVs}$

\begin{tabular}{lccc}
\hline Protein name & Uniprot & Score & Sequence \\
& AC & & coverage \\
\hline Ficolin-3 & O75636 & 8772 & 68 \\
Hemoglobin subunit alpha & P69905 & 1735 & 70 \\
Actin, cytoplasmic 1 & P60709 & 927 & 69 \\
Hemoglobin subunit beta & P68871 & 602 & 79 \\
Actin, gamma-enteric smooth muscle & $\mathrm{P} 63267$ & 500 & 32 \\
Talin-1 & $\mathrm{Q} 9$ Y490 & 368 & 50 \\
Filamin-A & $\mathrm{P} 21333$ & 353 & 40 \\
Spectrin alpha chain, erythrocytic 1 & $\mathrm{P} 02549$ & 321 & 42 \\
Myosin-9 & $\mathrm{P} 35579$ & 317 & 38 \\
Mannan-binding lectin serine protease 1 & $\mathrm{P} 48740$ & 308 & 35 \\
Band 3 anion transport protein & $\mathrm{P} 02730$ & 277 & 38 \\
Beta-actin-like protein 2 & $\mathrm{Q} 562 \mathrm{R} 1$ & 252 & 24 \\
Hemoglobin subunit delta & $\mathrm{P} 02042$ & 215 & 64 \\
Spectrin beta chain, erythrocytic & $\mathrm{P} 11277$ & 183 & 28 \\
Complement C1q subcomponent subunit C & $\mathrm{P} 02747$ & 170 & 24 \\
Ankyrin-1 & $\mathrm{P} 16157$ & 164 & 28 \\
CD5 antigen-like & $\mathrm{O} 43866$ & 164 & 52 \\
Integrin alpha-llb (CD41) & $\mathrm{P} 08514$ & 129 & 25 \\
Complement C1q subcomponent subunit B & $\mathrm{P} 02746$ & 122 & 41 \\
Deaminated glutathione amidase & $\mathrm{Q} 86 \times 76$ & 118 & 6 \\
\hline Preins & & & \\
\hline
\end{tabular}

2 Proteins in bold text indicate antigens identified using flow cytometry. This table excluded 3 immunoglobulin-related proteins and albumin. 


\section{Table 2 (on next page)}

Twenty most abundant proteins identified in urinary m/lEVs 
1 Table 2. Twenty most abundant proteins identified in urinary $\mathrm{m} / \mathrm{lEVs}$

\begin{tabular}{lccc}
\hline Protein name & Uniprot & Score & Sequence \\
& AC & & coverage \\
\hline Actin, cytoplasmic 1 & $\mathrm{P} 60709$ & 1618 & 67 \\
Neprilysin & $\mathrm{P} 08473$ & 1194 & 50 \\
Uromodulin & $\mathrm{P} 07911$ & 821 & 44 \\
Solute carrier family 12 member 1 & $\mathrm{Q} 13621$ & 720 & 32 \\
Alpha-enolase & $\mathrm{P} 06733$ & 708 & 79 \\
Moesin & $\mathrm{P} 26038$ & 548 & 73 \\
Ezrin & $\mathrm{P} 15311$ & 544 & 56 \\
Aminopeptidase N & $\mathrm{P} 15144$ & 486 & 43 \\
Actin, gamma-enteric smooth muscle & $\mathrm{P} 63267$ & 476 & 28 \\
Pyruvate kinase PKM & $\mathrm{P} 14618$ & 447 & 64 \\
Voltage-dependent anion-selective channel protein 1 & $\mathrm{P} 21796$ & 446 & 74 \\
Radixin & $\mathrm{P} 35241$ & 364 & 56 \\
Tyrosine-protein phosphatase non-receptor type 13 & $\mathrm{Q} 12923$ & 363 & 38 \\
Triosephosphate isomerase & $\mathrm{P} 60174$ & 325 & 80 \\
Multidrug resistance protein 1 & $\mathrm{P} 08183$ & 324 & 38 \\
Guanine nucleotide-binding protein G(I)/G(S)/G(T) subunit beta-2 & $\mathrm{P} 62879$ & 316 & 50 \\
Guanine nucleotide-binding protein G(I)/G(S)/G(T) subunit beta-1 & $\mathrm{P} 62873$ & 306 & 53 \\
V-type proton ATPase catalytic subunit A & $\mathrm{P} 38606$ & 298 & 57 \\
Superoxide dismutase [Cu-Zn] & $\mathrm{P} 00441$ & 285 & 91 \\
Epidermal growth factor receptor kinase substrate 8-like protein 2 & $\mathrm{Q} 9 \mathrm{H} 6 \mathrm{S3}$ & 277 & 43 \\
\hline & & & \\
\hline
\end{tabular}

2 Proteins in bold text indicate antigens identified using flow cytometry 


\section{Figure 1}

Isolation of m/IEVs from plasma and urine using differential centrifugation

( $A$ and $B$ ) Workflow of plasma (A) and urine (B) m/lEV isolation and sample preparation for flow cytometry analysis. (C-H) Isolated m/IEVs from plasma (C-E) and urine (F-H) were visualized by transmission electron microscopy. Arrow indicates representative m/IEVs (C and F). Microscopy was used to identify EV-like particles based on the size (100-400 nm) and shape (round) of the vesicles. The scale bar is shown.

\section{A Plasma $\mathrm{m} / \mathrm{lEVs}$ isolation workflow}

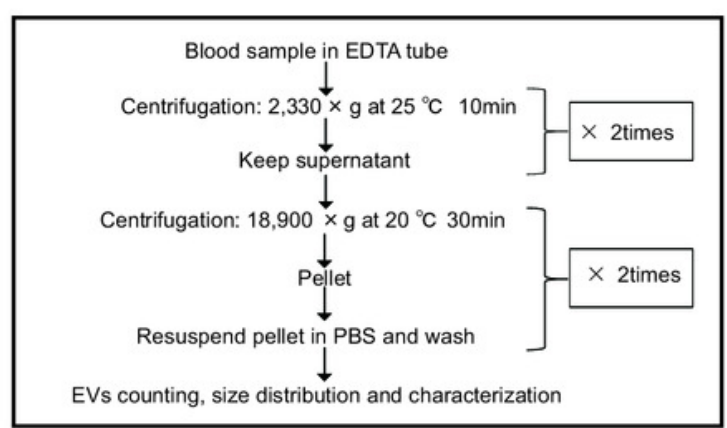

B Urine $\mathrm{m} / \mathrm{lEVs}$ isolation workflow

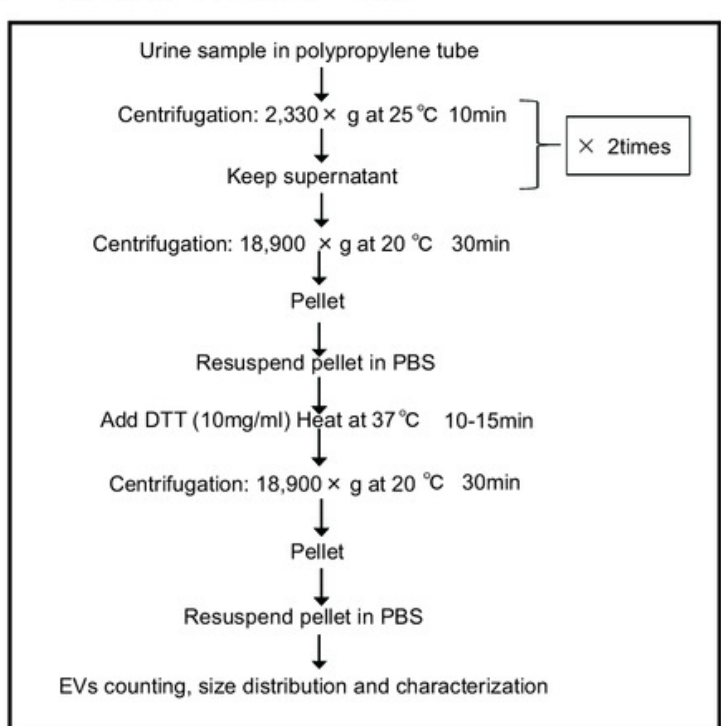

$\mathrm{C}$

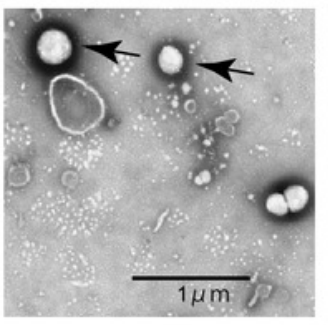

$\mathrm{D}$

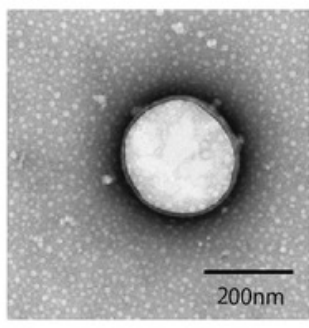

E

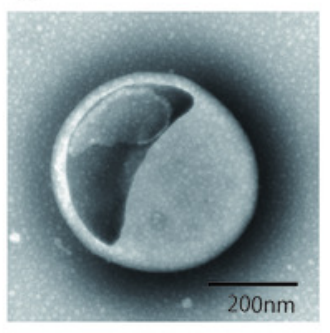

F

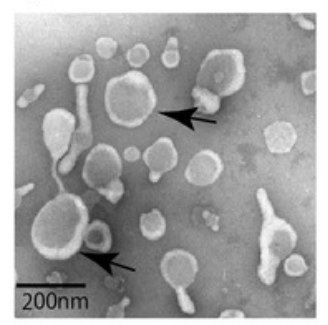

G

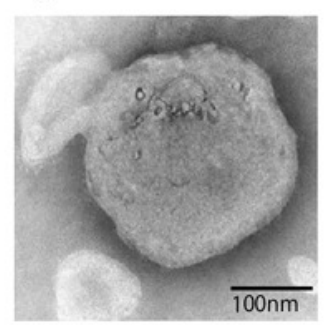

$\mathrm{H}$

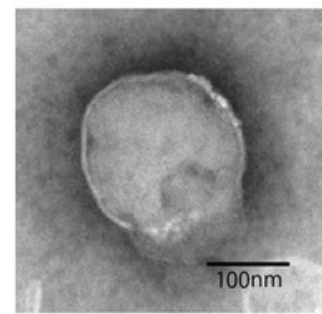




\section{Figure 2}

Flow cytometric analysis of plasma and urine m/lEVs

( $A$ and $B$ ) Analysis of plasma m/IEVs by flow cytometry. Forward and side scatter (SSC) were measured for plasma m/IEVs (A). The SSC distribution of plasma m/IEVs is shown as a histogram (indigo blue) compared with standard polystyrene beads (black histogram) (B). (C and D) Analysis of urine m/IEVs by flow cytometry. Forward and side scatter (SSC) were measured for urine $\mathrm{m} / \mathrm{IEVs}(\mathrm{C})$. The SSC distribution of urinary $\mathrm{m} / \mathrm{IEVs}$ is shown as a histogram (orange) compared with standard polystyrene beads (black histogram) (D). 


\section{Plasma m/lEVs}
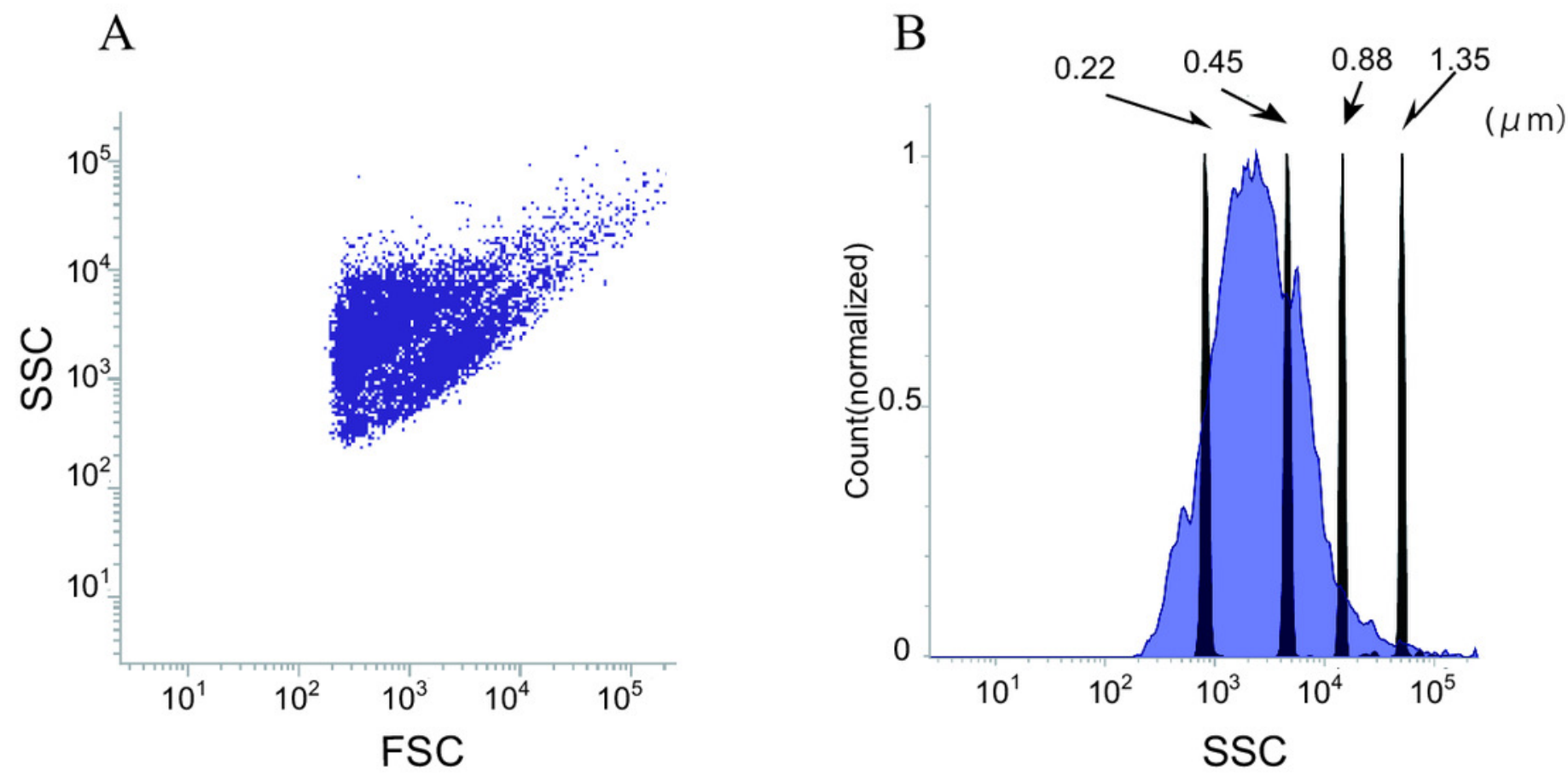

\section{Urine $\mathrm{m} / \mathrm{IEVs}$}
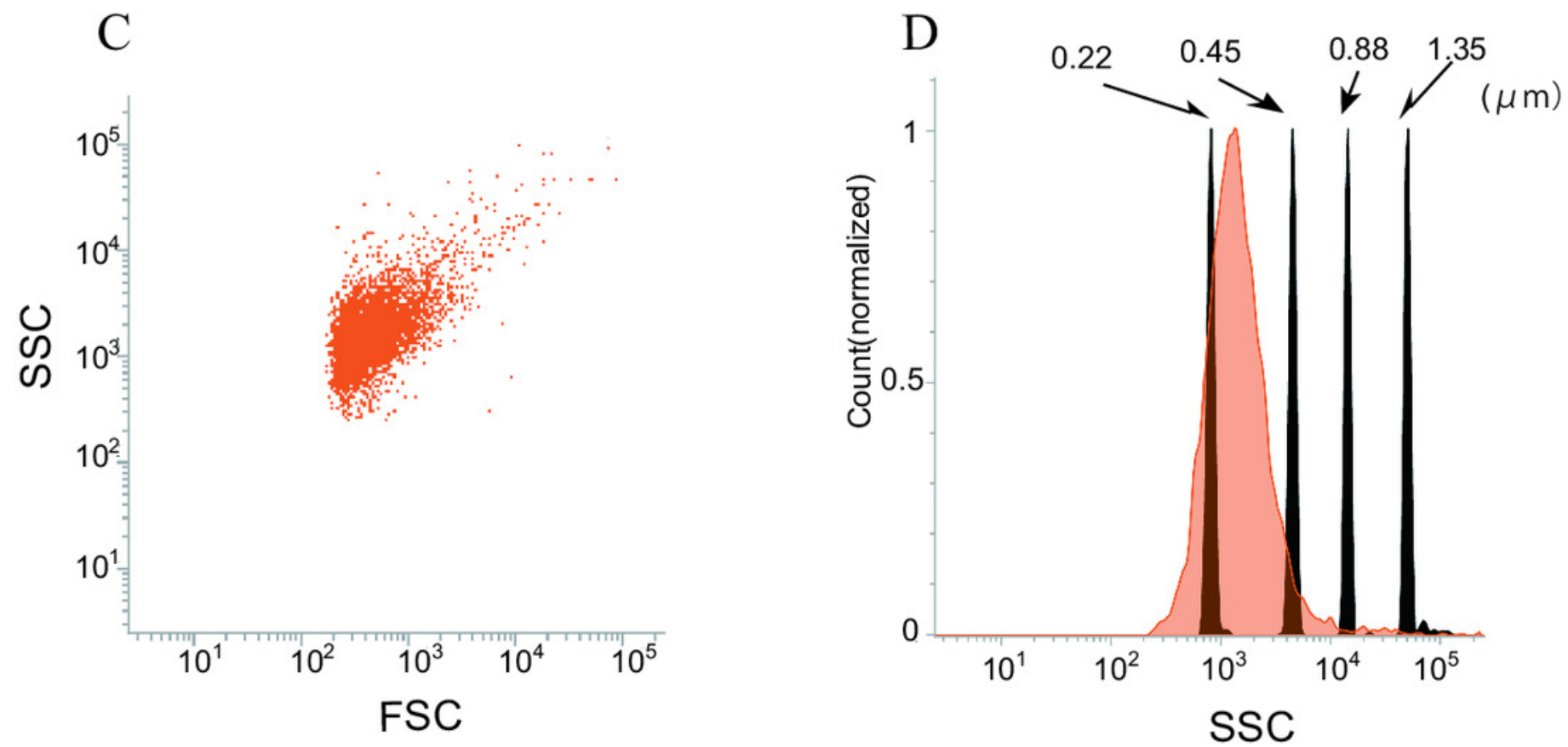


\section{Figure 3}

Shotgun proteomic analysis of plasma and urine m/IEVs

A. Protein extracts of $\mathrm{m} / \mathrm{IEV}$ s isolated from plasma and urine were analyzed by LC-MS/MS. A total of 593 and 1793 proteins from plasma and urine, respectively, were detected. Detailed lists of proteins are shown in S1 Table and S2 Table. B. GO (gene ontology) cellular components are shown for $\mathrm{m} / \mathrm{IEV}$ s isolated from plasma and urine using the DAVID program. Among the detected proteins, the gene list used for DAVID analysis included 588 proteins (plasma) and 1786 proteins (urine). The vertical axis shows the percentage of proteins from the full gene list categorized into each GO term. For example, for extracellular exosomes (plasma), the categorized count was 301 of 588 proteins. (C and D) Top 20 clusters from the Metascape pathway (http://metascape.org/) enrichment analysis for m/IEVs in plasma (C) and urine (D). Lengths of bars represent log10 ( $P$ values) based on the best-scoring term within each cluster. Among all detected proteins, 535 (plasma) and 1767 (urine) genes were recognized as unique for enrichment analysis. For each gene list, pathway and process enrichment analysis was carried out using the following ontology sources: KEGG Pathway, GO Biological Processes, Reactome Gene Sets, Canonical Pathways and CORUM. 
A

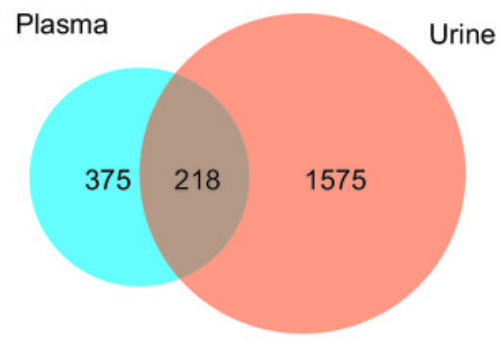

C Plasma $\mathrm{m} / \mathrm{IEVs}$ enrichment analysis
B

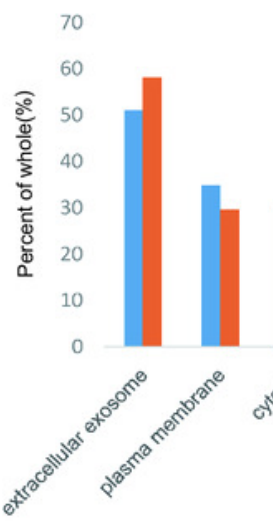

Cellular component

- Plasma Urine

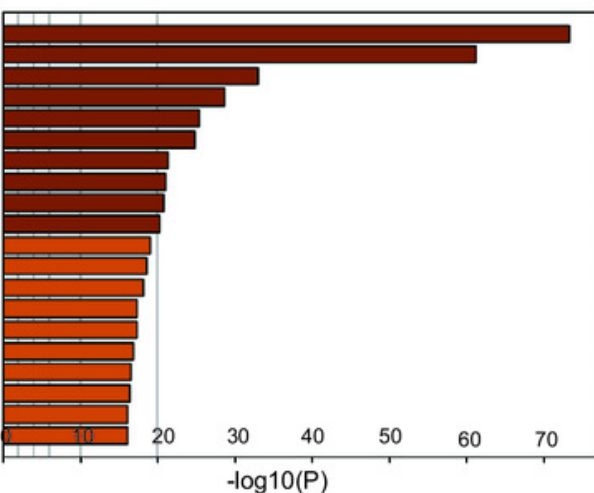

$-\log 10(P)$

GO:0045055: regulated exocytosis

\section{R-HSA-109582: Hemostasis}

hsa04610: Complement and coagulation cascades

GO:0002253: activation of immune response

GO:0030036: actin cytoskeleton organization

G0:0031589: cell-substrate adhesion

R-HSA-5653656: vesicle-mediated transport

60:0043062: extracellular structure organization

60:0060627: regulation of vesicle-mediated transport

GO:0050900: leukocyte migration

R-HSA-2173782: Binding and Uptake of Ligands by Scavenger Receptors

GO:0034330: cell junction organization

GO:0051235: maintenance of location

GO:0000904: cell morphogenesis involved in differentiation

hsa04611: Platelet activation

R-HSA-381426: Regulation of Insulin-like Growth Factor (IGF) transport and uptake by Insulin-like Growth Factor Bi

hsa04145: Phagosome

GO:0044403: symbiont process

D Urine $\mathrm{m} / \mathrm{EVVs}$ enrichment analysis

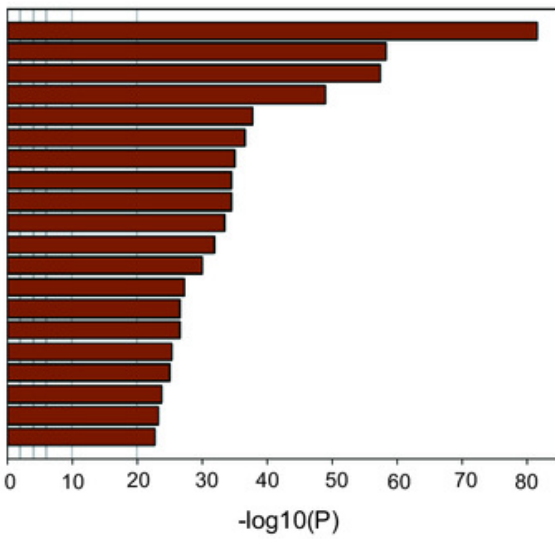

GO:0045055: regulated exocytosis

GO:0030029: actin filament-based process

R-HSA-5653656: Vesicle-mediated transport

GO:0051186: cofactor metabolic process

R-HSA-382551: Transport of small molecules

R-HSA-109582: Hemostasis

GO:0017144: drug metabolic process

GO:0120031: plasma membrane bounded cell projection assembly

R-HSA-422475: Axon quidance

GO:0060627: regulation of vesicle-mediated transport

GO:0044403: symbiont process

R-HSA 9006934 : Signeling by Receptor Tyrosine Kinases

GO:0044282: small molecule catabolic process

GO:1903827: regulation of cellular protein localization

GO:0051017: actin filament bundle assembly

ha 04810: Regulation of actin cytoskeleton

GO:0072657: protein localization to membrane

60.0007265: Ras protein signal transduction

GO:0051640: organelle localization

$-\log 10(P)$ 


\section{Figure 4}

Characterization of plasma $\mathrm{m} / \mathrm{IEV}$ s by flow cytometry

A. Two specific surface antigens were used to characterize the $\mathrm{m} / \mathrm{IEV}$ from each source by flow cytometry. m/IEVs were characterized by comparison with five types of blood cells using surface antigens and Annexin V staining. (B-L). Representative dot plots (SSC vs. Annexin V). Each plot was classified by staining for surface antigens and Annexin $\mathrm{V}(\mathrm{C}-\mathrm{L})$ and an overall plot summarizing the data (B) is shown. M. Quantification of each m/IEV by flow cytometry analysis ( $\mathrm{n}=10$ for human healthy plasma, \% of total events). ( $\mathrm{N}-\mathrm{Q}$ ). Comparison of Annexin $\mathrm{V}$ staining for erythrocyte-(N), macrophage-(O), platelet-(P) and T and B cell-(Q) derived $\mathrm{m} / \mathrm{IEVs}$ from ten healthy plasma samples. Comparisons were performed using the Wilcoxon signed-rank test $(* p<0.05, * * p<0.01$; a value of $p<0.05$ was considered to indicate statistical significance). 
A Plasma m/lEVs characterized by multi CD antigen

\begin{tabular}{|c|c|c|c|c|c|c|c|c|c|c|}
\hline & \multirow[t]{2}{*}{ Annexin5 } & CD59 & CD235a & CD41 & \begin{tabular}{|l|} 
CD61 \\
\end{tabular} & CD15 & \multirow{2}{*}{\begin{tabular}{|c|} 
CD45 \\
LCukoyye \\
Common \\
Antigen \\
\end{tabular}} & CD5 & CD105 & CD146 \\
\hline & & $\begin{array}{l}\text { - Protectin } \\
\text { - MIRL }\end{array}$ & $\begin{array}{c}\text { - Glycophorin } \\
\text { A }\end{array}$ & $\begin{array}{c}\text { - Integrin } \\
\text { allb }\end{array}$ & \begin{tabular}{|c|} 
- Integrin \\
$\beta 3$
\end{tabular} & \begin{tabular}{|l|}
-Lewis $x$ \\
- SSEA-1 \\
\end{tabular} & & - Leu-1 & Endoglin. & -Muc 18 \\
\hline \multirow[t]{2}{*}{ Erythrocyte derived } & + & + & + & & & & - & & & \\
\hline & - & + & + & & & & - & & & \\
\hline \multirow{2}{*}{ Platelet derived } & + & & & + & + & & - & - & & \\
\hline & - & & & + & + & & - & - & & \\
\hline \multirow{2}{*}{$\begin{array}{l}\text { Macrophage/Monocyte/Granulocyte } \\
\text { derived }\end{array}$} & + & & - & & & + & + & & & \\
\hline & - & & - & & & + & + & & & \\
\hline \multirow[t]{2}{*}{$T$ and $B$ cell derived } & + & & - & & & & + & + & & \\
\hline & - & & - & & & & + & + & & \\
\hline \multirow[t]{2}{*}{ Endothelial Cell derived } & + & & & & & & & & + & + \\
\hline & - & & & & & & & & + & + \\
\hline
\end{tabular}
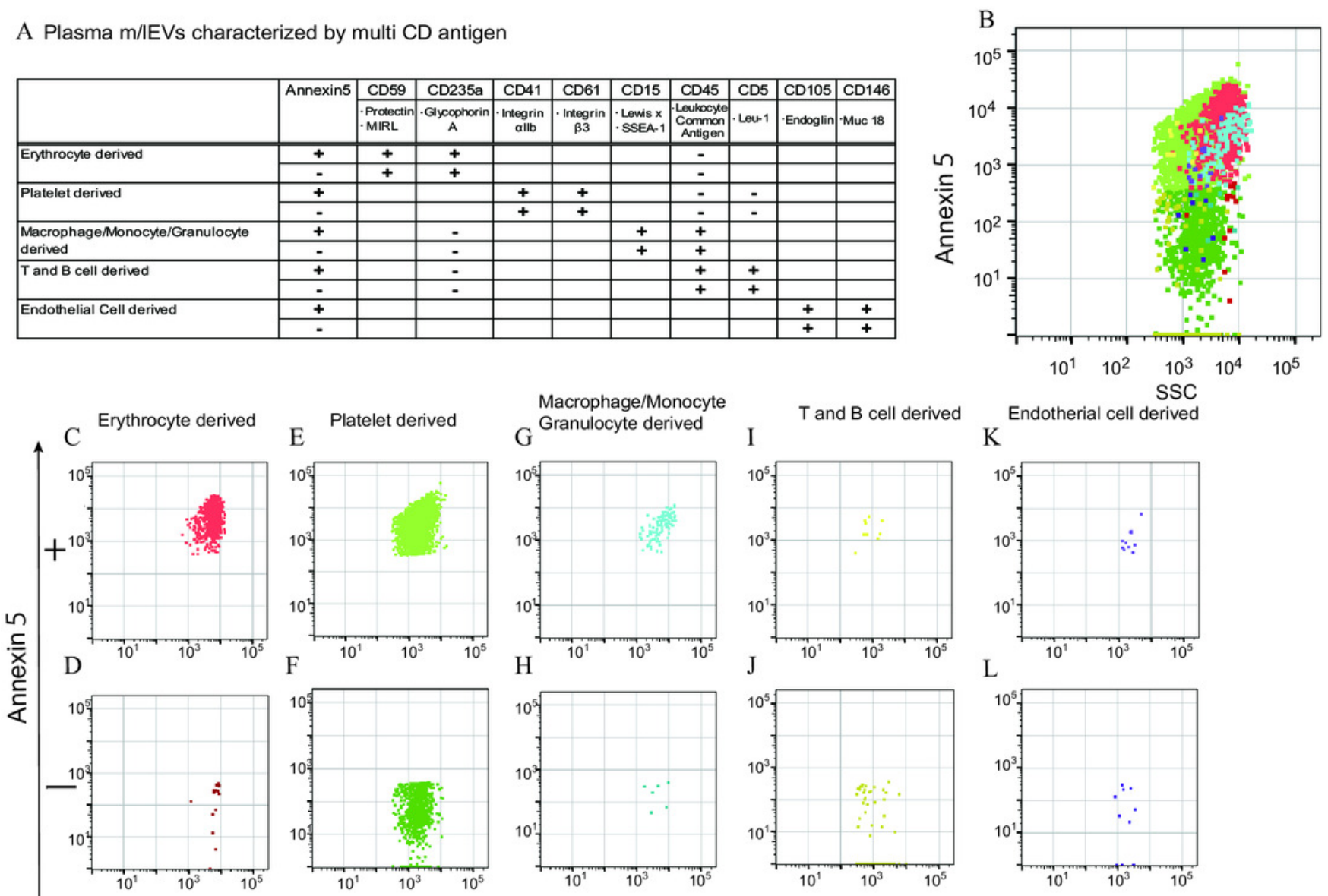

$\mathrm{K}$
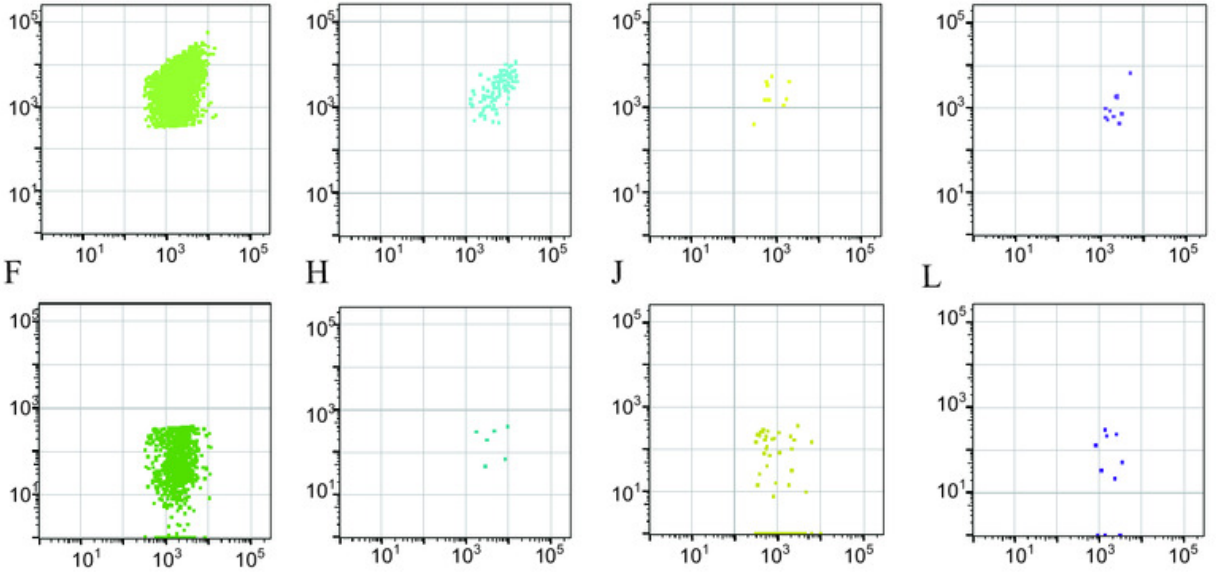

$\mathrm{L}$

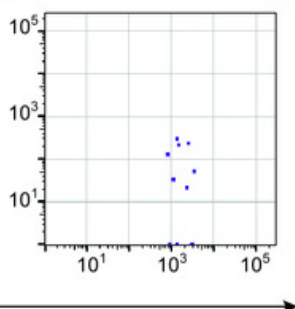

SSC

M

Characterized $\mathrm{m} / \mathrm{IEVs}$ ratio in 10 healthy plasma

\begin{tabular}{|c|c|c|c|c|}
\hline$(\mathrm{N}=10)$ & Annexin5 & Average(\%) & SD & range (\%) \\
\hline \multirow[t]{2}{*}{ Erythrocyte derived } & + & $10 \%$ & $4.2 \%$ & $2.8-16$ \\
\hline & - & $0.16 \%$ & $0.25 \%$ & $0-0.84$ \\
\hline \multirow[t]{2}{*}{ Platelet derived } & + & $19 \%$ & $8.2 \%$ & $4.6-30$ \\
\hline & - & $16 \%$ & $10 \%$ & $2.6-32$ \\
\hline \multirow{2}{*}{$\begin{array}{l}\text { Macrophage/Monocyte/Granulocyte } \\
\text { derived }\end{array}$} & + & $0.43 \%$ & $0.49 \%$ & $0.02-1.3$ \\
\hline & - & $0.07 \%$ & $0.10 \%$ & $0-0.31$ \\
\hline \multirow[t]{2}{*}{$T$ and $B$ cell derived } & + & $0.19 \%$ & $0.24 \%$ & $0.01-0.77$ \\
\hline & - & $0.50 \%$ & $0.40 \%$ & $0.05-1.4$ \\
\hline \multirow[t]{2}{*}{ Endothelial Cell derived } & + & $0.08 \%$ & $0.05 \%$ & $0.02-0.2$ \\
\hline & - & $0.03 \%$ & $0.03 \%$ & $0.01-0.09$ \\
\hline
\end{tabular}

Platelet derived

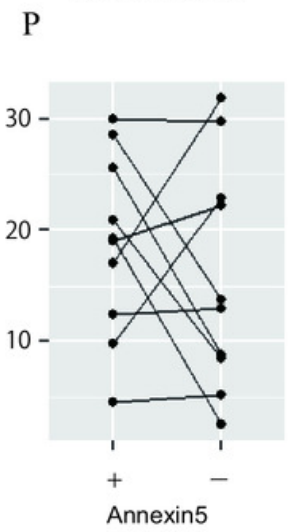

T and $\mathrm{B}$ cell derived

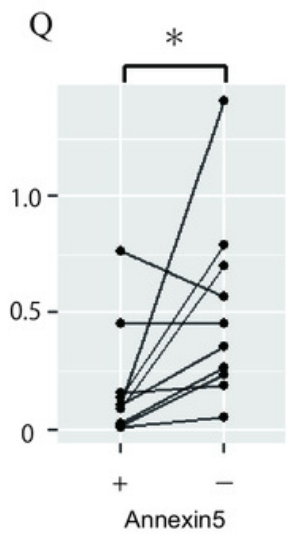

$\mathrm{N}$

Erythrocyte derived

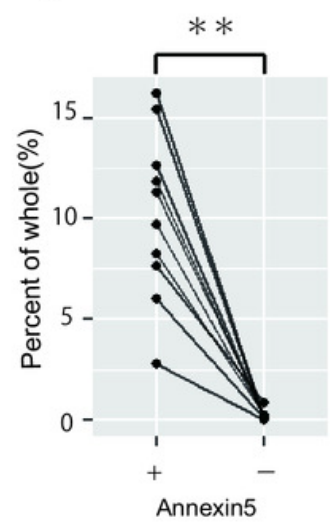

O Macrophage/Monocyte

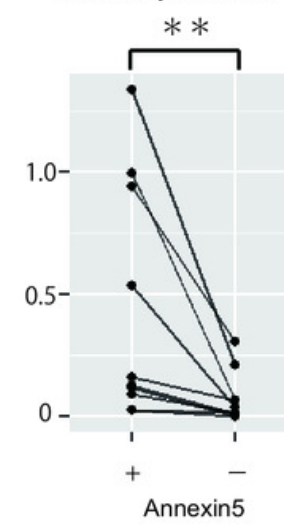




\section{Figure 5}

Characterization of urinary m/IEVs by flow cytometry and CD26 enzymatic activity

A. Two kinds of $\mathrm{m} / \mathrm{IEV}$ in urine were characterized by using surface antigen and Annexin $\mathrm{V}$ staining. (B-F). Representative dot plots in the observation area (SSC vs Annexin V). Each plot was classified according to staining for multiple peptidases [CD10 (neprilysin), CD13 (alanine aminopeptidase) and CD26 (DPP4)] (C and D), and CD277 (MUC-1) (E and F). Events were further classified as Annexin V positive or negative. G. Quantification of m/lEVs by flow cytometry analyses ( $n=10$ for male human healthy urine, \% of total events). ( $\mathrm{H}$ and I). Comparison of Annexin V staining for MUC1-positive (H) and multiple peptidase-positive (I) $\mathrm{m} / \mathrm{IEVs}$ in the urine of ten healthy male human samples. Comparisons were performed using the Wilcoxon signed-rank test $(* P<0.05$, $* * P<0.01$; a value of $p<0.05$ was considered to indicate statistical significance). J. DPP4 enzymatic activity was assessed for urinary m/IEVs. The workflow for fractionating $\mathrm{m} / \mathrm{IEVs}$ by centrifugation is shown. (K and L). Quantification of DPP4 activity in urine (K) and plasma ( $L$ ) fractions ( $n=6$ for human healthy male urine and plasma, \% of whole). The percentage of enzyme activity measured for each fraction compared with whole activity is shown. 
A Urine $\mathrm{m} / \mathrm{IEV}$ s characterized by multi $C D$ antigen

\begin{tabular}{|c|c|c|c|c|c|}
\hline & \multirow[t]{2}{*}{ Annexin5 } & \multirow{2}{*}{\begin{tabular}{c|} 
CD10 \\
'neutral \\
endopeptidase \\
'Neprilysin \\
\end{tabular}} & \multirow{2}{*}{\begin{tabular}{|c|}
$\mathrm{CD} 13$ \\
$\because$ Amino \\
peptidase N
\end{tabular}} & \multirow{2}{*}{$\begin{array}{c}\text { CD26 } \\
\text { - Dipeptidyl I } \\
\text { Peptidase-4 } \\
\text { (DPFV) }\end{array}$} & \multirow{2}{*}{$\begin{array}{l}\text { CD227 } \\
\begin{array}{c}\text { Mucin } 1 \\
\text { (MuC1) }\end{array}\end{array}$} \\
\hline & & & & & \\
\hline \multirow[t]{2}{*}{ Multiple peptidase positive } & + & + & + & + & - \\
\hline & - & + & + & + & - \\
\hline \multirow[t]{2}{*}{ MUC1 positive } & + & & - & & + \\
\hline & & & 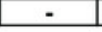 & & + \\
\hline
\end{tabular}

G Characterized m/IEVs ratio in 10 healthy male urine

\begin{tabular}{|c|c|c|c|c|}
\hline$(\mathrm{N}=10)$ & Annexin5 & Average(\%) & SD & range $(\%)$ \\
\hline Multiple peptidase (CD10,CD13,CD26) & + & $10 \%$ & $9.0 \%$ & $2.2-28$ \\
\hline positive & - & $38 \%$ & $17 \%$ & $11-68$ \\
\hline \multirow[t]{2}{*}{ MUC1 positive } & + & $5.2 \%$ & $3.4 \%$ & $2.0-12$ \\
\hline & - & $3.2 \%$ & $2.6 \%$ & $0.82-9.4$ \\
\hline
\end{tabular}

C Multiple peptidase

B
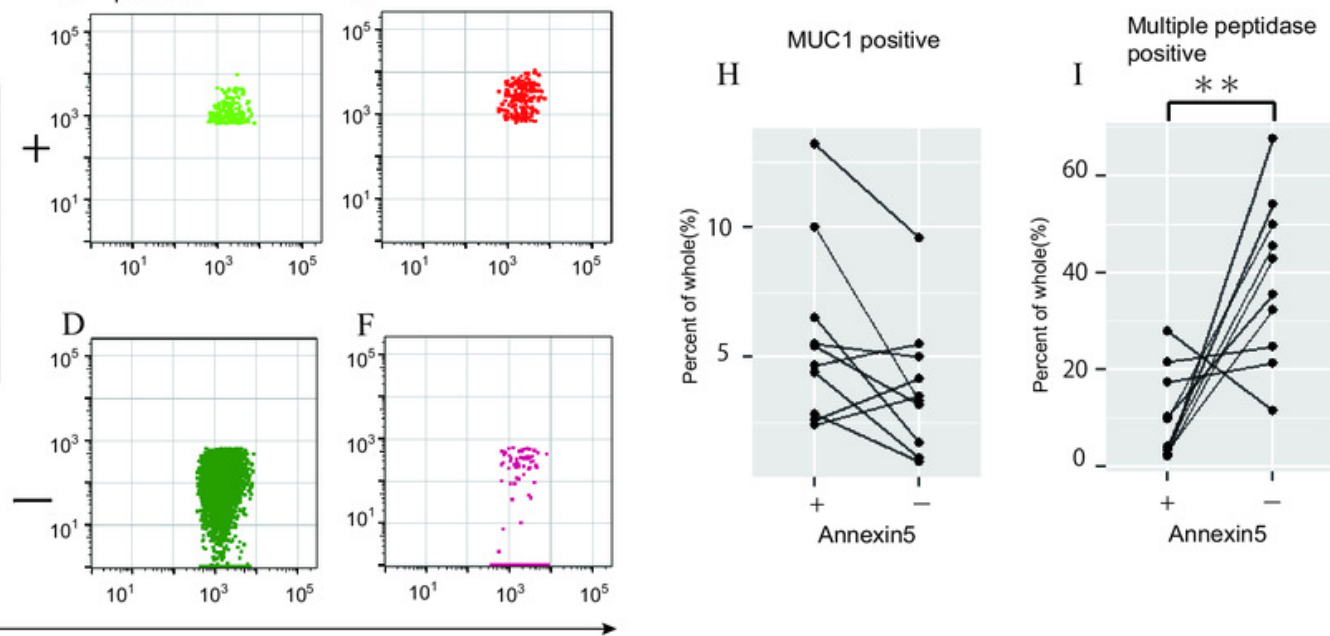

SSC

J DPP4(CD26) activity of plasma and urine m/IEVs

Blood sample in EDTA tube or Urine sample in polypropylene tube Centrifugation: $2,330^{\perp} \times \mathrm{g}$ at $25^{\circ} \mathrm{C} \quad 10 \mathrm{~min}$

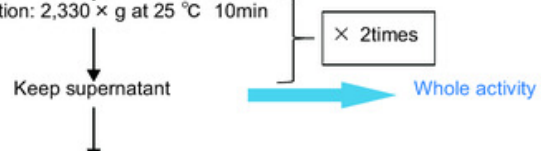

Centrifugation: $18,900 \times \mathrm{g}$ at $20^{\circ} \mathrm{C} 30 \mathrm{~min}$

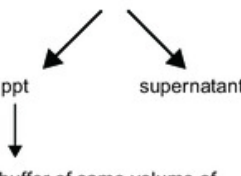

Supernatant activity

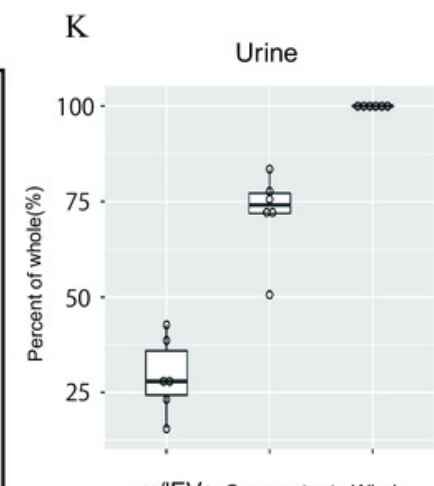

L

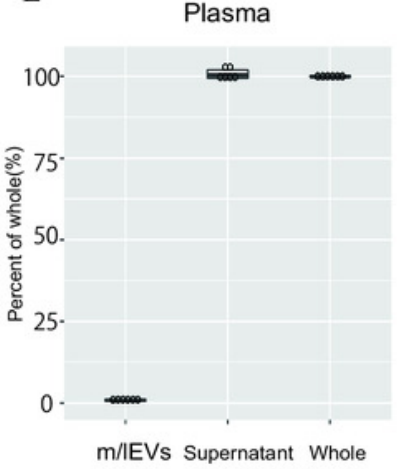

